\title{
Synthesis and Antioxidant Activities of Schiff Bases and Their Complexes: An Updated Review
}

\author{
Sayed Suliman Shah ${ }^{1}$, Dawood Shah ${ }^{1}$, Ibrahim Khan ${ }^{2 *}$, Sajjad Ahmad ${ }^{1}$, Umar Ali $^{1}$, Atiq ur Rahman ${ }^{1}$ \\ 1 Department of Chemistry, Government Degree College No.2 Mardan (23200), Affiliated with Abdul Wali Khan \\ University Mardan KP, Pakistan \\ 2 Department of Biotechnology, School of Life Sciences and Technology, University of Electronic Science and Technology \\ of China (610054) Chengdu, China \\ * Correspondence: ibrahimkhan.qau@yahoo.com;
}

Scopus Author ID 57191379139

Received: 18.04.2020; Revised: 22.05.2020; Accepted: 24.05.2020 Published: 1.06.2020

\begin{abstract}
Schiff bases are chemical compounds formed from the condensation reaction of aldehydes or ketones with amines. These compounds are majorly used in industries and also have significant biological activities, including antioxidant, antibacterial, antifungal, antiviral, antitumor, and antiinflammatory. The majority of these compounds show excellent catalytic activities. Schiff bases are considered to be the most versatile ligands as they form complexes with the metal atoms. They are called privileged ligands because these compounds can be synthesized simply by condensation. The complexes of copper, zinc, and cadmium are the essential metallic complexes of these compounds. Schiff bases and its metallic complexes are instrumental in scavenging the free radicals and thus protect living bodies from the adverse effects of these radicals. Due to the recent exhaustive study on Schiff bases, it becomes an independent filed of research in chemistry. These compounds are widely investigated; however, the antioxidant properties of these compounds needs further investigation. In this review, we investigate various synthesis mechanisms of Schiff bases and their essential antioxidant activities. We also explore the metallic complexes of some most essential Schiff bases and their effects on living cells. The present study will be valuable to provide a foundation for antioxidant characterization of Schiff bases and for future studies on Schiff bases to synthesize high-quality antioxidant compounds.
\end{abstract}

Keywords: Schiff bases; antioxidant; free radicals; metal complexes; scavenging activity; amines.

( 2020 by the authors. This article is an open-access article distributed under the terms and conditions of the Creative Commons Attribution (CC BY) license (https://creativecommons.org/licenses/by/4.0/).

\section{Introduction}

Schiff bases are a class of compounds containing the 'Azomethine' as a functional group that contains a carbon-nitrogen double bond $(>\mathrm{C}=\mathrm{N}-)$, nitrogen being attached to an alkyl or aryl group, but not hydrogen [1]. These compounds were reported by a German Chemist Hugo Schiff in 1864 and therefore referred to his name [2]. The majority of the Schiff bases are represented by the general formula $\mathrm{R}_{1} \mathrm{R}_{2} \mathrm{C}=\mathrm{NR}_{3}$ [3], while some of these have the general formula $\mathrm{R}_{1} \mathrm{CH}=\mathrm{NR}_{2}$, in which carbon is attached with a hydrogen atom instead of an alkyl or aryl group [4]. These are condensation products of ketones or aldehydes with primary amines [5]. Usually, stable Schiff bases are those which are formed from the condensation reaction of aromatic amines and aromatic aldehydes [6].

Schiff bases have been reported to possess a number of biological activities including antifungal [7], analgesic [8], anti-inflammatory [9], antibacterial [10], antioxidant [11], antitumor [12], cardiovascular [13], antitubercular [14] and used as local painkillers [15]. Their 
biological activities depend upon the type of substituent attached to the aromatic ring. In recent years, the attention of Schiff bases, as well as their metallic complexes, is increasing due to their remarkable catalytic and biological applications [16]. Schiff bases also function as versatile ligands and can coordinate with a number of metal atoms or ions in various oxidation states and geometries. Schiff bases can form complexes with d-block elements and lanthanides [17]. Schiff bases are capable of coordinating with metal ions via the imine nitrogen and other groups linked to the Schiff base [18]. Schiff bases are called privileged ligands since they can be prepared simply by condensation between aldehydes and primary amines [19]. Most of the Schiff bases have Nitrogen or Oxygen donor atoms, but sometimes sulfur or selenium can replace Oxygen atom [20]. Schiff bases may serve as monodentate, bidentate, tridentate or tetradentate ligands depending upon the number of donor atoms present in the molecule. They can make chelates (typically five or six-membered) on reaction with metal ion [21]. Some of the Schiff bases in combinations with metal ions are used as insecticides, fungicides, and herbicides [22].

Antioxidants are naturally occurring chemical substances that protect the living body from damage caused by harmful molecules called free radicals. These are produced by body cells in response to free radicles [23, 28]. The free radicals play a significant role in the etiology of numerous diseases, including cancer, diabetes, liver injury, autoimmune disorders, cardiac diseases, atherosclerosis, and aging [24]. Therefore antioxidants that have the potential to scavenge the free radicals play a significant role in the curing and preventions of these diseases [25]. Antioxidants are widely used as catalysts in antibiotics such as anti-inflammatory, antifungal, antibacterial, antivirus and in industries as anticorrosion [26]. Nowadays, synthetic antioxidants have major use as compared to natural antioxidants because they are cheaper and effective [27]. For example, $\mathrm{Co}(\mathrm{II}), \mathrm{Ni}(\mathrm{II})$, and $\mathrm{Cu}(\mathrm{II})$ complexes of (Z)-2-(pyrrolidin-2ylidene) hydrazine carbothioamide (L) have greater free radical scavenging capacity. Stable 1,1-diphenyl-2-picryl-hydrazyl (DPPH) free radical was used to determine the free radical scavenging ability of these complexes [29]. Until now, there are no comprehensive reports available on the antioxidant activities of the Schiff base and their possible metallic complexes. This review aims to explore the synthesis and antioxidant activities of some critical Schiff bases and their metallic complexes. The present study will be valuable to provide a foundation for antioxidant characterization of Schiff bases and for future studies on Schiff bases to synthesize high-quality antioxidant compounds.

\section{Synthesis and antioxidant activities of Schiff bases}

Antioxidant compounds have high free radical scavenging capacity. Antioxidants play a significant role in delaying or preventing the oxidation of easily oxidable substances (substrates) [30, 31]. In living bodies, antioxidant compounds prevent the harm to macromolecules and cells by interfering with the free radical molecules [32]. Therefore, the importance of searching for antioxidants has dramatically increased in recent years [33]. Presently, synthetic antioxidants are broadly used as compared to natural antioxidants as they are cheaper and effective [34]. In this review, several Schiff bases and their metal complexes have been explored as effective antioxidants.

Neelofar et al. have reported the synthesis of two Schiff bases namely 2-[(2-hydroxynaphthalen-1-ylmethylene)-amino]-3-(1H-imidazol-4-yl)-propionic acid (HNLH), synthesized from the reaction of 2-hydroxy-1-naphthaldehyde and L-histidine, and 4-[(2-hydroxynaphthalen-1-ylmethylene)-amino] $N$-(4methyl-pyrimidin-2-yl)-benzenesulfonamide (HNSM) 
synthesized from the condensation reaction of 2-hydroxy-1-naphthaldehyde with sulfamethazine. They also synthesized tin(II) complexes of HNLH and HNSM (Scheme 1). The antioxidant potential of the ligands and their metal complexes was determined using 1,1diphenyl-2-picryl-hydrazyl (DPPH) method. The results declare that the ligand HNLH and its complex have higher $\mathrm{IC}_{50}$ value as compared to HNSM and its complex. The amount of antioxidant necessary to reduce DPPH concentration by $50 \%$ is a commonly used parameter to measure antioxidant activity and is referred to as $\mathrm{IC}_{50}$. The lower the $\mathrm{IC}_{50}$ value, the higher is the antioxidant activity. The IC 50 values of the ligands and their complexes are given in Table $1[35]$.

Table 1. Antioxidant activities of ligands and their corresponding complexes.

\begin{tabular}{l|l|l}
\hline Compound & IC $_{\mathbf{5 0}}$ value $(\mathbf{p p m})$ & Inference \\
\hline $\mathrm{HNLH}$ & 1405.97 & antioxidant \\
\hline$\left[\mathrm{Sn}(\mathrm{HNLH}) \mathrm{Cl}_{2}\left(\mathrm{H}_{2} \mathrm{O}\right)\right]$ & 2031.04 & antioxidant \\
\hline $\mathrm{HNSM}$ & 118.87 & antioxidant \\
\hline$\left[\mathrm{Sn}(\mathrm{HNSM}) \mathrm{Cl}_{2}\left(\mathrm{H}_{2} \mathrm{O}\right)_{2}\right]$ & 361.16 & antioxidant \\
\hline
\end{tabular}
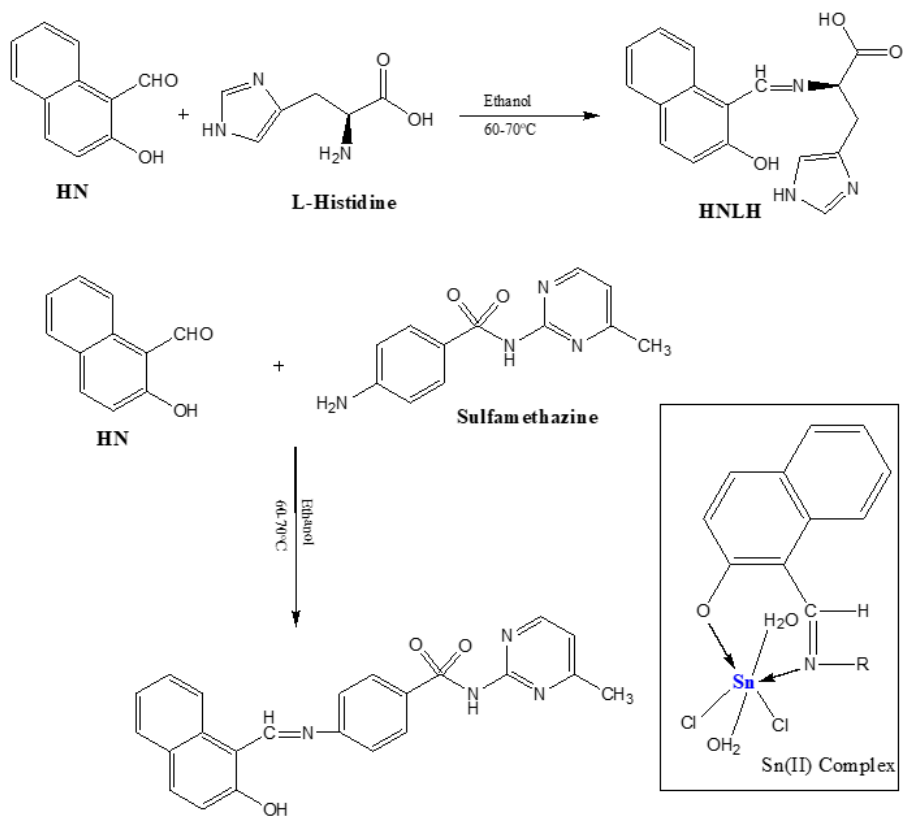

HNSM

Scheme 1. Synthesis of the Schiff bases HNLH, HNSM, and Sn(II).

Wahab et al. synthesized Schiff bases: SP-5 (Benzylidene aniline), by the condensation of benzaldehyde with aniline, and SP-18 (Benzylidene urea) by the condensation of benzaldehyde and urea in the presence of natural acid extracted from tamarind and lemon (Scheme 2). The antioxidant activity of SP-5 and SP-18 was determined using DPPH method (Table 2) [36].

Table 2. Antioxidant activity of SP-5 and SP-18.

\begin{tabular}{l|l|l}
\hline Samples & \%Inhibition \pm SD & IC \\
\hline SP-5 $\mathbf{~ u g} / \mathbf{m l}$ \\
\hline SP-18 & $69 \pm 0.01$ & 937.5 \\
\hline
\end{tabular}


<smiles>Nc1cccc(C=Cc2ccccc2)c1</smiles><smiles>NC(=O)N=Cc1ccc(O)cc1</smiles>

Scheme 2. Synthetic procedure of SP-5 and SP-18.

Six different Chitosan-based Schiff bases (CSBs) have been reported synthesized by the condensation reaction of chitosan/O-CMC with nitro and chloro substituted salicylaldehydes [37]. The free radical scavenging ability of CSBs was determined against superoxide and hydroxide radicals. From the reaction of cavacral aldehyde and eugenol aldehyde with chitosan, two CSBs have been synthesized. The antioxidant capacities of the compounds were evaluated using DPPH assay. The result showed that the complex of cavacral aldehyde had low antioxidant activities as compared to the CSB of eugenol aldehyde [38]. Ying et al. derived CSB from D-fructose, and chitosan showed better scavenging ability against DPPH radical [39].

$\mathrm{Hu}$ et al. have been reported the synthesis of a novel Schiff base: N-(methyl-2benzimidazolmethylidene)-2-hydroxyanaline (L), from the condensation reaction of 2acetylbenzimidazole and 2-aminophenol, and its copper complexes with the general formula $\left[\mathrm{CuL}_{2} \mathrm{NO}_{3}\right] \mathrm{NO}_{3} .2 \mathrm{C}_{2} \mathrm{H}_{5} \mathrm{OH}$ (I) and $\left[\mathrm{CuLNO}_{3}\right]_{2} \cdot 2 \mathrm{C}_{2} \mathrm{H}_{5} \mathrm{OH}$ (II) (Scheme 3). The characterization of the products formed was performed using Infrared and ${ }^{1} \mathrm{H}-\mathrm{NMR}$ spectroscopic techniques, elemental analysis, and X-ray diffraction technique. The results indicated that I is mononuclear, and II have a binuclear structure. Superoxide and hydroxide free radical scavenging activities were used to study the antioxidant activity of the complexes and ligand. The results showed that the complexes are better antioxidants as compared to the Schiff base, while I is a better antioxidant than II [40].

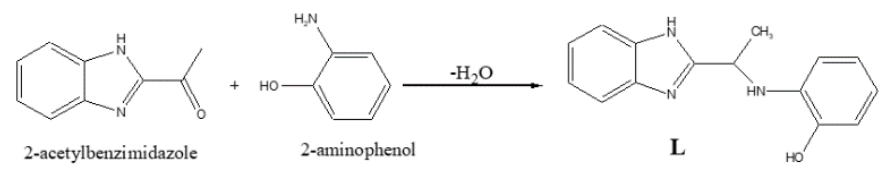

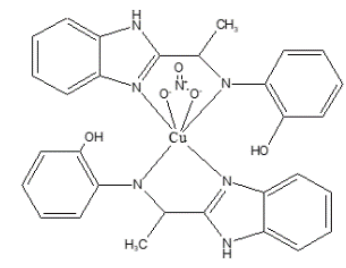

I

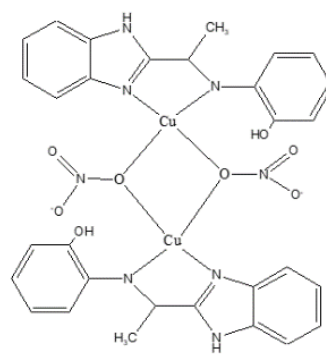

II

Scheme 3. Synthesis of Schiff base L and complex I and II. 
Dilek Unluer et al. synthesized two new Schiff base derivatives with morpholines, 4bromo-2-(((4-morpholinophenyl)imino)methyl)phenol (I) and 4-bromo-2-(((2morpholinoethyl)imino)methyl)phenol (II). 4-Morphinolin-4-yl-cycloexylamine and 5-bromo2-hydroxybenzaldehyde were reacted to synthesize (I). The compound (II) was synthesized by mixing equimolar solutions of 2-morpholinoethan $(0.01 \mathrm{~mol})$ and 5-bromo-2hydroxybenzaldehyde $(0.01 \mathrm{~mol})$ and (Scheme 4$)$. Antioxidant activities of compounds (I) and (II) were determined by the FRAP assay method in which TPTZ-Fe(III) complex get reduced to TPTZ-Fe(II) complex which is based on the reduction of Fe3+-TPTZ complex to the Fe2+ -TPTZ. It was found that compound I has relatively high antioxidant activity than compound II [41]. TPTZ stands for (2,4,6-tris(2- pyridyl)-s-triazine).

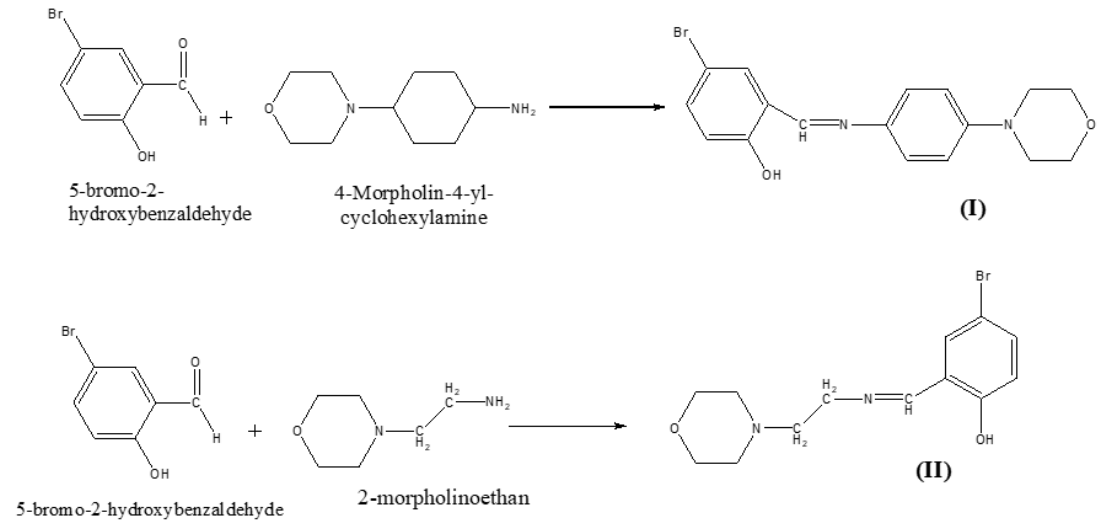

Scheme 4. Reactions for the synthesis of compound (I) and (II).

A new Schiff base, namely N-(4-phenylthiazol-2-yl)-2-(thiophene-2-ylmethylene) hydrazinecarboxamide and its $\mathrm{M}(\mathrm{II})$ complexes, $(\mathrm{M}=\mathrm{Ni}, \mathrm{Cu}, \mathrm{Zn}$, and $\mathrm{Co})$, have been reported to have significant antioxidant activities [42].

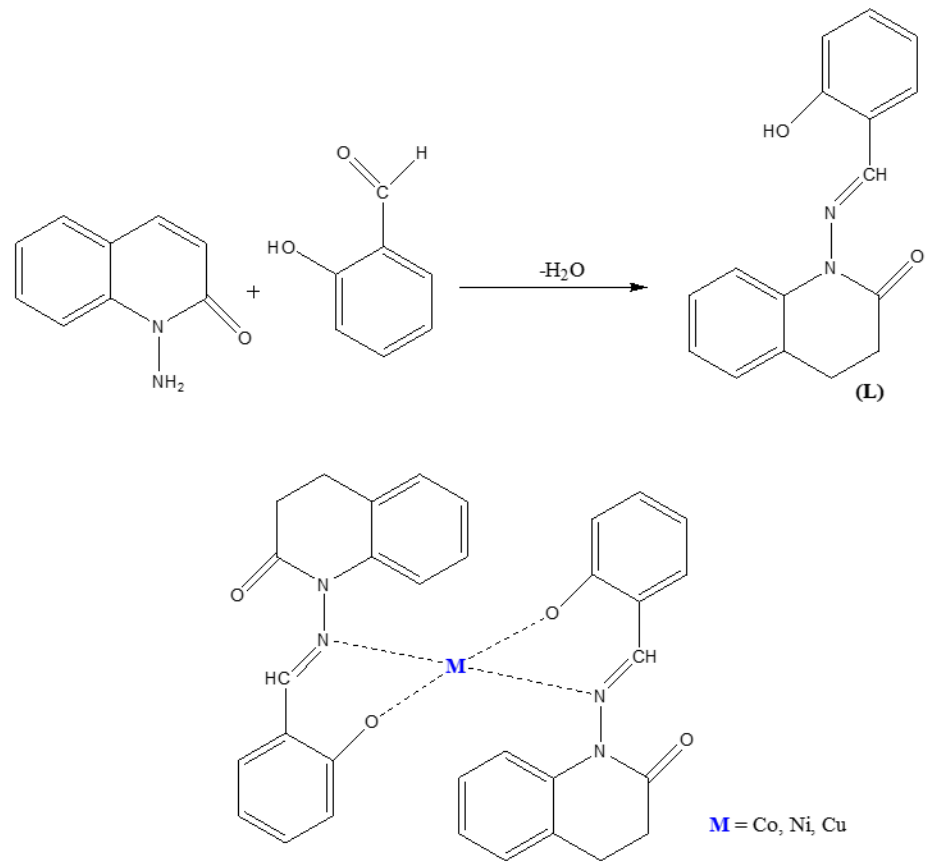

Scheme 5. Synthesis scheme of the Schiff base (L) and proposed structure of complexes.

Azawi et al. synthesized a series of Schiff base metal complexes by the condensation of $\mathrm{MCl}_{2} \cdot \mathrm{nH}_{2} \mathrm{O}(\mathrm{M}=\mathrm{Co}, \mathrm{Ni}, \mathrm{Cu})$ with 1-((2hydroxybenzylidene)amino)quinolin-2(1H)-one. Schiff base: 1-(2hdroxybenzylidene) amino) quinolin-2(1H)-one $(\mathrm{L})$, was synthesized from a mixture of $\mathrm{N}$-aminoquinolone $(0.8 \mathrm{~g}, 0.005 \mathrm{~mol})$ and $(0.005 \mathrm{~mol})$ 2-hydroxybenzaldehyde. The 
Schiff base complexes ([Co(L1) $\left.{ }_{2} \mathrm{Cl}_{2}\right]$ ( I), $\left[\mathrm{Ni}(\mathrm{L} 1)_{2} \mathrm{Cl}_{2}\right]$ (II) and $\left[\mathrm{Cu}(\mathrm{L} 1)_{2} \mathrm{Cl}_{2}\right]$ (III)) with metals $(\mathrm{Co}, \mathrm{Ni}$, and $\mathrm{Cu})$ were synthesized by adding the salts $[\mathrm{CoCl} 2.6 \mathrm{H} 2 \mathrm{O}, \mathrm{NiCl} 2.6 \mathrm{H} 2 \mathrm{O}$ and $\mathrm{CuCl} 2.2 \mathrm{H} 2 \mathrm{O}]$ dissolved in ethyl alcohol to an ethanolic solution of the synthesized Schiff base: 1-((2-hydroxybenzylidene)amino)quinolin-2(1H)-one (L), in (2:1) mole ratio ligand to metal $[\mathrm{M} / \mathrm{L}]$ respectively, with stirring (Scheme 5).

The scavenging activity of 1-((2-hydroxybenzylidene)amino)quinolin-2(1H)-one metal complexes, ([Co(L1) $\left.)_{2} \mathrm{Cl}_{2}\right] \mathrm{I},\left[\mathrm{Ni}(\mathrm{L} 1)_{2} \mathrm{Cl}_{2}\right]$ II and $\left[\mathrm{Cu}(\mathrm{L} 1)_{2} \mathrm{Cl}_{2}\right]$ III) were estimated based on Fenton reaction. The scavenging activity of the complexes was determined using $\mathrm{H}_{2} \mathrm{O}_{2}$. It was observed that these complexes have high hydroxyl free radical scavenging activity [43].

The Schiff base: (Z)-2-(2-methoxybenzylideneamino)-3-methylbutanoic acid along with its nickle(II) and cobalt(II) metal complexes have been synthesized (Scheme 6). Antioxidant activities of the compounds were evaluated using DPPH method. The results revealed that the $\mathrm{Ni}$ (II) complex was the higher antioxidant relative to the other synthesized complex [44].

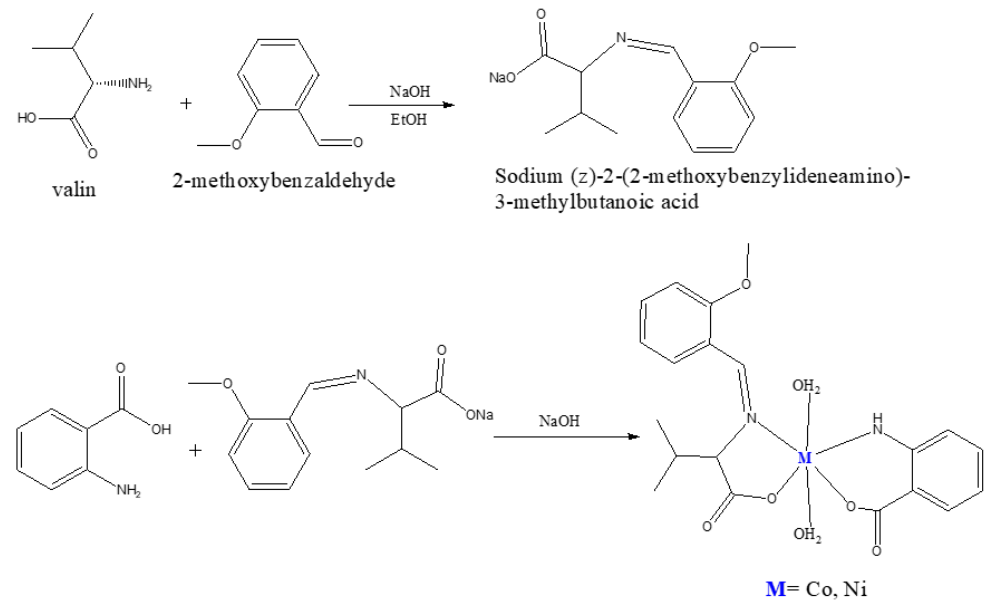

Scheme 6. Synthetic procedure of the Schiff bases and its Co(II) and Ni(II) complexes.

Schiff base: (4E)-4-[(2-\{(E)-[1-(2,4-dihydroxyphenyl) ethylidene $]$ amino $\}$ ethyl $)$ imino]pentane-2-one ( $\left.\mathrm{H}_{2} \mathrm{LL}\right)$ and its $\mathrm{M}(\mathrm{II})$ complexes have been reported. Where $\mathrm{M}=\mathrm{Co}, \mathrm{Ni}$, $\mathrm{Zn}$, and $\mathrm{Cu}$ (Scheme 7). The prepared ligand and complexes were characterized by infrared spectroscopy, electronic spectroscopy, elemental analysis, and X-ray diffraction (XRD). DPPH and ABTS methods were used to estimate the antioxidant properties of the prepared compounds. The results revealed that the $\mathrm{Cu}$ (II) complex was the most active antioxidant [45].

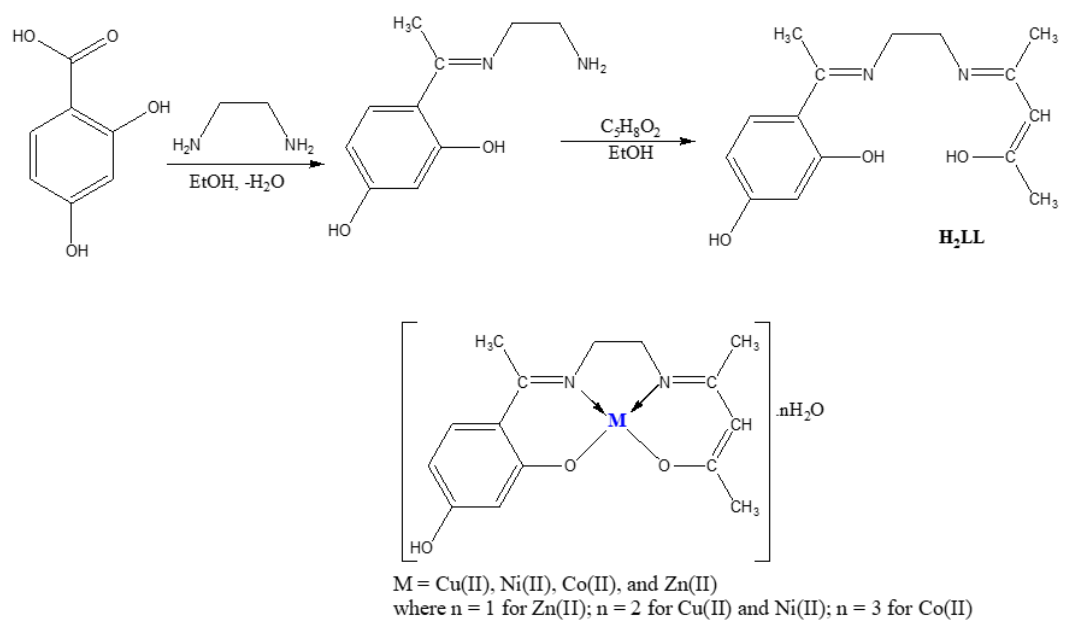

Scheme 7. Synthesis of Schiff base $\left(\mathrm{H}_{2} \mathrm{LL}\right)$ and its metal complexes. 
The synthesis of phenyl urea derivatives (1a-1c) from substituted anilines has been reported. The Schiff bases $(2 \mathrm{a}-2 \mathrm{c})$ were synthesized from phenyl urea derivatives when they were reacted with 4-methoxybenzaldehyde. The Schiff bases were treated with chloroacetyl chloride in suitable solvents to synthesize the corresponding azitinides (3a-3c) (Scheme 8). All the synthesized compounds were characterized by Gas chromatography-mass spectrometry (GCMS), FT-IR (Fourier transform infrared spectroscopy), thin-layer chromatography (TLC), ${ }^{1} \mathrm{H}$-NMR and ${ }^{13} \mathrm{C}$-NMR. The Schiff base and azetidine were screened for in-vitro antioxidant activity by employing hydrogen peroxide free-radical inhibition method. These compounds showed significant antioxidant effects relative to ascorbic acid. The names of the Schiff bases and azitinides are given in Table 3 [46].

Table 3. IUPAC names of the Schiff bases and azitinides.

\begin{tabular}{c|c|c|l}
\hline S. No. & Schiff base/Azitinide & Compound & IUPAC name \\
\hline 1 & Schiff base & $2 \mathrm{a}$ & $\begin{array}{l}\text { 1-(4-methoxyphenyl)-3-[(1E)-2-(pyrimidin-5-yl) } \\
\text { ethylidene] urea }\end{array}$ \\
\hline 2 & Schiff base & $2 \mathrm{~b}$ & $\begin{array}{l}\text { N-(4-methoxyphenyl)-N'-[(1E)-2-(4-methylphenyl) } \\
\text { ethylidene]urea }\end{array}$ \\
\hline 3 & Schiff base & $2 \mathrm{c}$ & $\begin{array}{l}\text { 1-[(1E)-2-(3-fluorophenyl) ethylidene]-3-(4- } \\
\text { methoxyphenyl) urea }\end{array}$ \\
\hline 4 & Azitinide & $3 \mathrm{a}$ & $\begin{array}{l}\text { 3-chloro-N-(4-methoxyphenyl)-2-oxo-4-(pyrimidin- } \\
\text { 5-yl)azetidine-1-carboxamide }\end{array}$ \\
\hline 5 & Azitinide & $3 \mathrm{~b}$ & $\begin{array}{l}\text { 3-chloro-N-(4-methoxyphe nyl )-2- } \\
\text { methylphenyl)-4-oxoazetidine-1-carboxamide }\end{array}$ \\
\hline 6 & Azitinide & $3 \mathrm{c}$ & $\begin{array}{l}\text { 3-chloro-2-(3-fluorophenyl)-N-(4-methoxyphenyl)- } \\
\text { 4-oxoazetidine-1-carboxamide }\end{array}$ \\
\hline
\end{tabular}
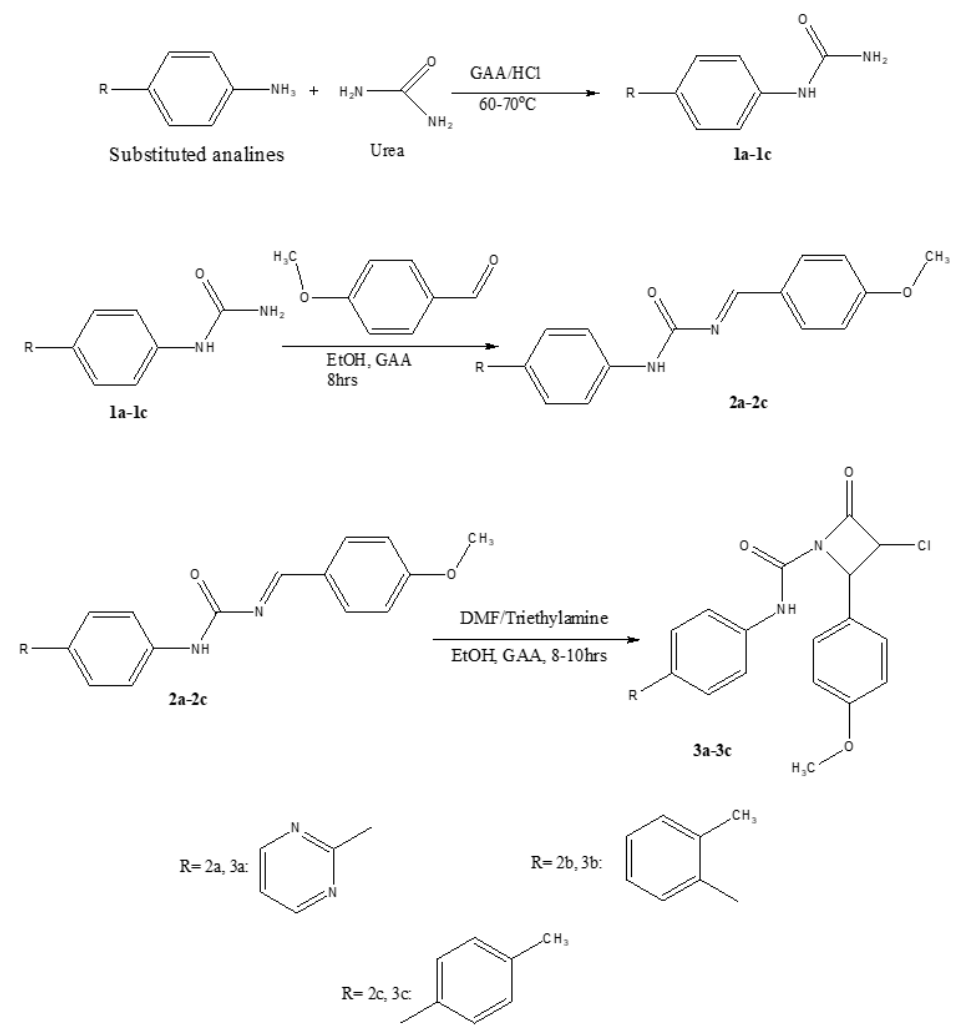

Scheme 8. Synthesis of the compound $1 \mathrm{a}-1 \mathrm{c}, 2 \mathrm{a}-2 \mathrm{c}$ and $3 \mathrm{a}-3 \mathrm{c}$.

Two Schiff bases and its $\mathrm{Cu}$ (II) complexes (complex-1 and complex-2) having the general formula [Cu(II)L1L2] have been reported. The L1 and L2 are different in both complexes. In complex-1(L1= Schiff base prepared from the reaction of 2,6-diaminopyridine and o-hydroxybenzaldehyde, L2 = L-cysteine) and in complex-2 (L1= Schiff base prepared from the reaction of L-histidine and vanillin, $\mathrm{L} 2=2,6$-diaminopyridine). The compounds were 
characterized by FT-IR spectra. The antioxidant activities of the synthesized Schiff base ligands and their complexes were evaluated using $\mathrm{H}_{2} \mathrm{O}_{2}$ method. The results showed that the percentage of scavenging activity was minimum as compared to their metal $(\mathrm{Cu}(\mathrm{II}))$ complexes (Table 4) (Figure 1) [47].

Table 4. Antioxidant activity of synthesized compounds.

\begin{tabular}{c|c|c|c|c}
\hline \multirow{2}{*}{ Concentrations } & \multicolumn{4}{|c}{ \% of antioxidant scavenging activity } \\
\cline { 2 - 5 } & Ligand-1 & Ligand-2 & Complex-1 & Complex-2 \\
\hline $2 \mathrm{mg}$ & $11 \%$ & $08 \%$ & $39 \%$ & $28 \%$ \\
\hline $4 \mathrm{mg}$ & $19 \%$ & $10 \%$ & $58 \%$ & $37 \%$ \\
\hline $6 \mathrm{mg}$ & $23 \%$ & $12 \%$ & $65 \%$ & $46 \%$ \\
\hline $8 \mathrm{mg}$ & $27 \%$ & $15 \%$ & $78 \%$ & $52 \%$ \\
\hline
\end{tabular}

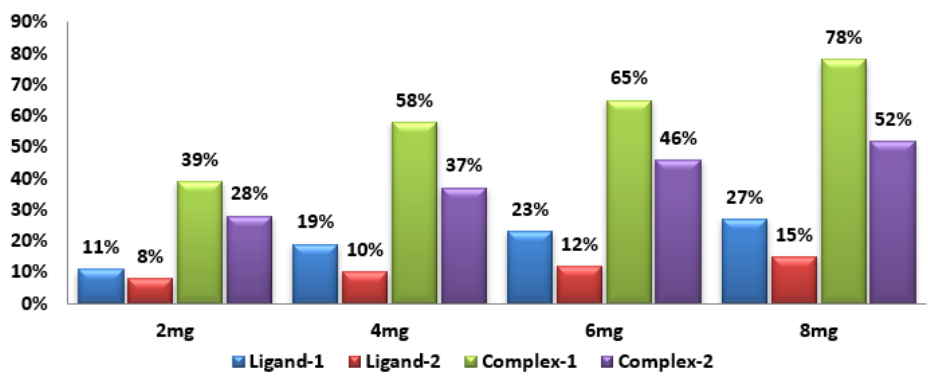

Figure 1. Histogram for the antioxidant activity.

The Schiff base ligand: (2-\{(E)-[(4-chlorophenyl) imino] methyl $\}$ phenol) and its M(II) complexes $(\mathrm{M}=\mathrm{Cu}, \mathrm{Ni}, \mathrm{Zn}$, and $\mathrm{Co})$ have been synthesized, and the antioxidant properties were studied using FRAP method, DPPH method, FIC (Ferrous ion chelation) method, phosphomolybdenum method and by hydroxyl free radical $\left({ }^{\circ} \mathrm{OH}\right)$ scavenging activity (Scheme 9). It was observed that the synthesized compounds show significant antioxidant properties as compared to conventional antioxidants, i.e., Vitamin-C and EDTA [26].

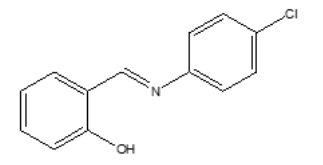

(2-\{(E)-[(4-chlorophenyl)imino]methyl\}phenol)
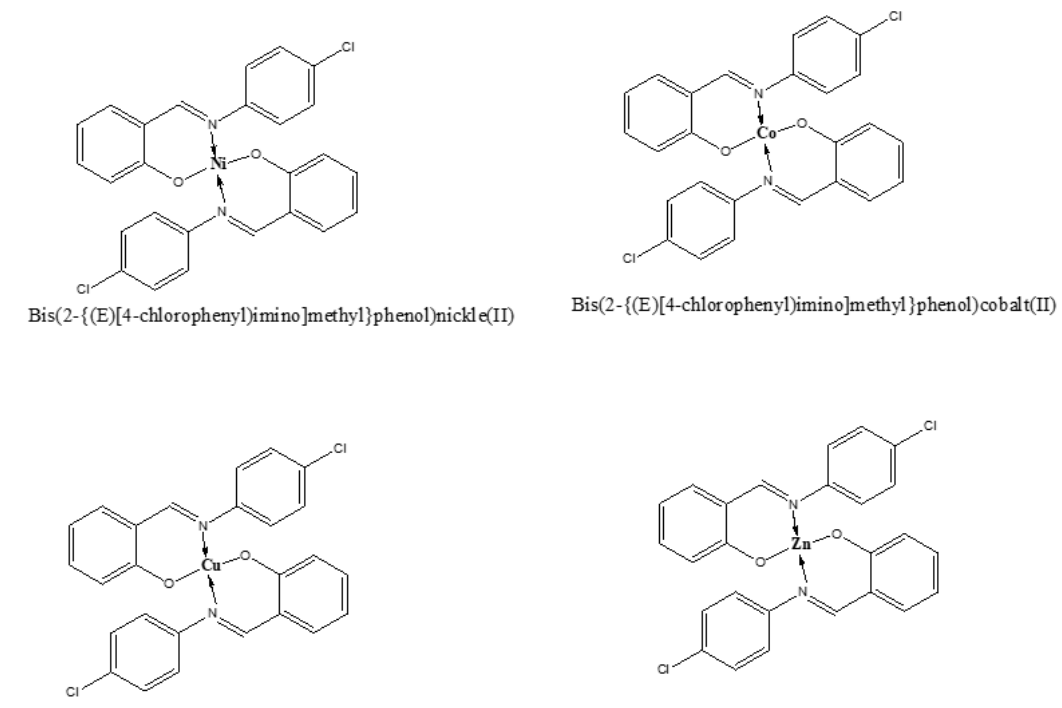

$\operatorname{Bis}(2-\{(E)[4-c h l o r o p h e n y l) i m i n o] m e t h y l\}$ phenol $)$ cupper(II)

$\operatorname{Bis}(2-\{(E)[4-c h l o r o p h e n y l) i m i n o] m e t h y l\}$ phenol $)$ zinc(II)

Scheme 9. Chemical structure of Schiff base, and Copper (II), Nickel (II), Zinc (II), Cobalt (II), metals complexes. 
A series of new Schiff bases of isatin and its derivatives have been synthesized from substituted aldehydes, isatin, and thiocarbohydrazide. The synthesized complexes and ligand were characterized by means of infrared spectroscopy, elemental analysis, ${ }^{1} \mathrm{H}-\mathrm{NMR}$, and ${ }^{13} \mathrm{C}$ NMR. The antioxidant properties of all the compounds were evaluated by DPPH free radical scavenging method. Two types of products were synthesized, monosubstituted products (compounds 1-5) synthesized from thiocarbohydrazide, and aromatic aldehydes (Scheme 10) and disubstituted products (compounds 6-10) synthesized from monosubstituted products which were bounded with isatin group (Scheme 11). The antioxidant activity was evaluated individually in two different steps: monosubstituted products and disubstituted products. It was observed that the compound 3 and 4 showed the highest oxidation activity and the antioxidant effect of disubstituted Schiff base products was suppressed due to isatin group [48].

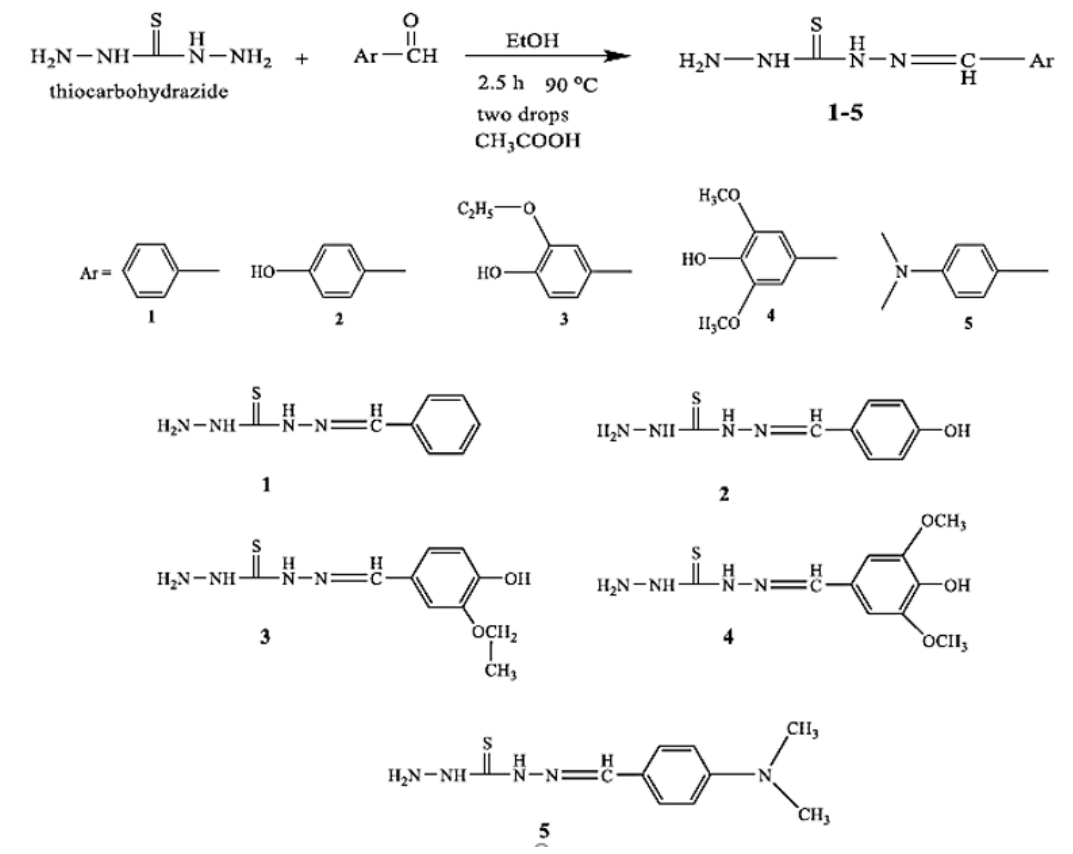

Scheme 10. Synthesis of monosubstituted products (compound 1-5).
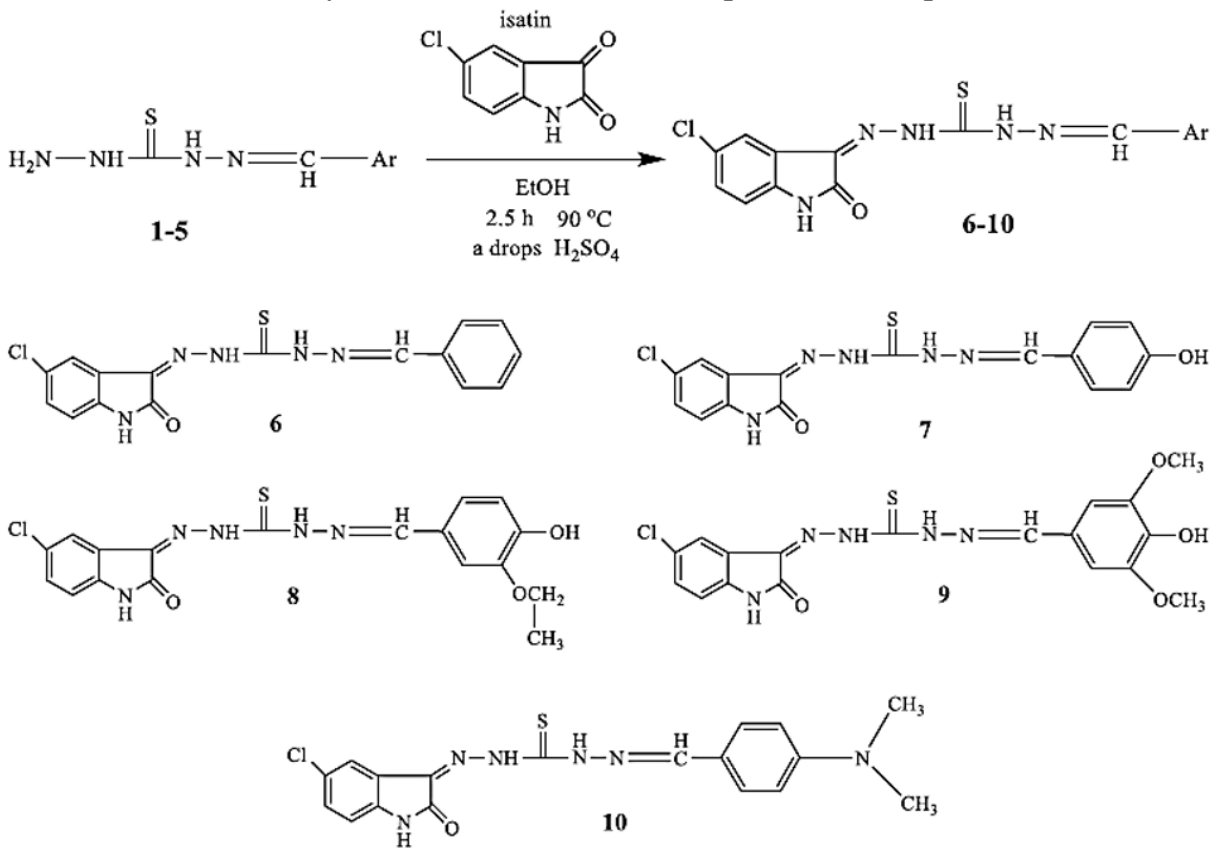

Scheme 11. Synthesis of disubstituted products (compound 6-10). 
Two novel Copper (II) complexes have been reported by Boulguemh et al. having the general formula $\left[\mathrm{Cu}(\mathrm{L})_{2}\right](\mathbf{I})$, where $\mathrm{L}=$ Schiff base: $\mathrm{N}^{\prime}$-(propan-2-ylidene)thiopene-2carbohydrazide (HL) and $\left[\mathrm{Cu}_{2}(\mu-\mathrm{Cl})_{2}(\mathrm{HL})_{2} \mathrm{Cl}_{2}\right]$ (II), where $\mathrm{L}=\mathrm{HL}$. The complex (I) was prepared by the condensation reaction of the Schiff bases HL and mononuclear salt of copper while the complex (II) was synthesized by the condensation reaction of the HL and doubly chloro bridged dinuclear salt of copper (Scheme 12). The products prepared were characterized by infrared spectroscopy and single-crystal X-ray analysis. CUPRAC and ABTS methods were used to evaluate the antioxidant properties of both complexes. It was observed that complex (I) is more efficient than complex (II). But the $\mathrm{IC}_{50}$ values of both compounds were higher than the $\mathrm{IC}_{50}$ values of the reference compounds butylated hydroxyl toluene (BHT) and butylated hydroxyl anisole (BHA) [49].

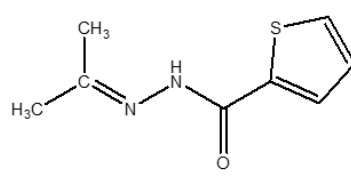

HL
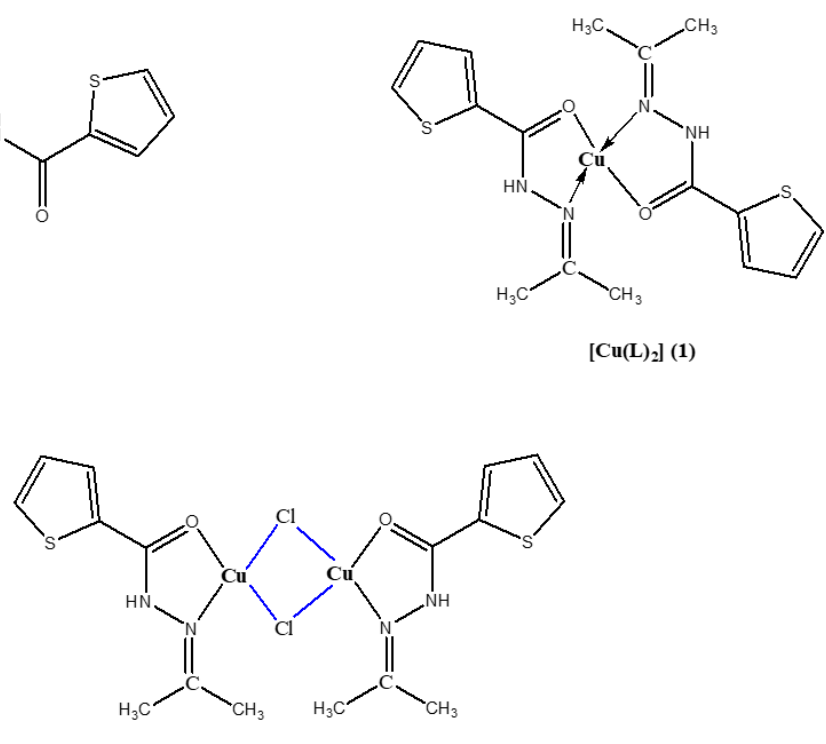

$\left[\mathrm{Cu}_{2}(\mu-\mathrm{Cl})_{2}(\mathrm{HL})_{2} \mathrm{Cl}_{2}\right](2)$

Scheme 12. Proposed structure of the Schiff base (HL) and $\mathrm{Cu}(\mathrm{II})$ complexes.

Bingöl and Turan synthesized a new Schiff base ligand: 6-Acetylamino-2-[(2-hydroxy3-methoxy-benzylidene)-amino]-4, 5, 6, 7-tetrahydro-benzo[b]thiophene-3-carboxylic acid methylester, from methyl 6-acetamide-2-amino-4, 5, 6, 7-tetrahydrobenzo[ $b]$ thiophene-3carboxylate and 2-hydroxy-3-methoxybenzaldehyde (Scheme 13). $\mathrm{NiCl}_{2} \cdot 6 \mathrm{H}_{2} \mathrm{O}, \mathrm{PdCl}_{2}$ $\left(\mathrm{CH}_{3} \mathrm{CN}\right)_{2}, \mathrm{FeCl}_{2} .4 \mathrm{H}_{2} \mathrm{O},\left[\mathrm{RuCl}_{2} \text { (p-cymene) }\right]_{2}$, and $\mathrm{CoCl}_{2} .6 \mathrm{H}_{2} \mathrm{O}$ metal salts were used to prepare the complexes with Schiff base (Scheme 14). The products were characterized by ultravioletvisible spectroscopy, Fourier transform infrared spectroscopy, ${ }^{13} \mathrm{C}-\mathrm{NMR}$ and Proton nuclear magnetic resonance spectroscopy, thermogravimetric analysis (TGA) and elemental analysis. FRAP method, CUPRAC method, DPPH method were used to study the antioxidant activities of the compounds, and the total antioxidant power was determined using the ferric thiocyanate (FTC) method. The results showed that the complexes are more effective antioxidants as compared to the Schiff base ligand [50].

Yuksel et al. reported two Schiff base monomers 4-[((7-hydroxynaphthalene-1yl)imino)methyl]benzene-1,2-diol (1), synthesized from the reaction of 8-amino-2-naphthol and 2,4-dihydroxybenzaldehyde, and 4-[((7-hydroxynaphthalene-1-yl)imino)methyl]benzene1,3-diol, synthesized from the reaction of 8-amino-2-naphthol and 3,4dihydroxybenzaldehyde. Then these monomers were converted into their corresponding polymers ( 3 and 4 ) by the oxidation reaction with $\mathrm{NaOCl}$ (Scheme 15). The products formed (1-4) were characterized Fourier transform infrared spectroscopy and proton nuclear magnetic 
resonance spectroscopy. The antioxidant properties of products $1-4$ were evaluated using ABTS, DPPH, and FRAP methods. The standard antioxidants used were ascorbic acid and $\mathrm{E}(\alpha-$ tocopherol) (Table 5) [51].

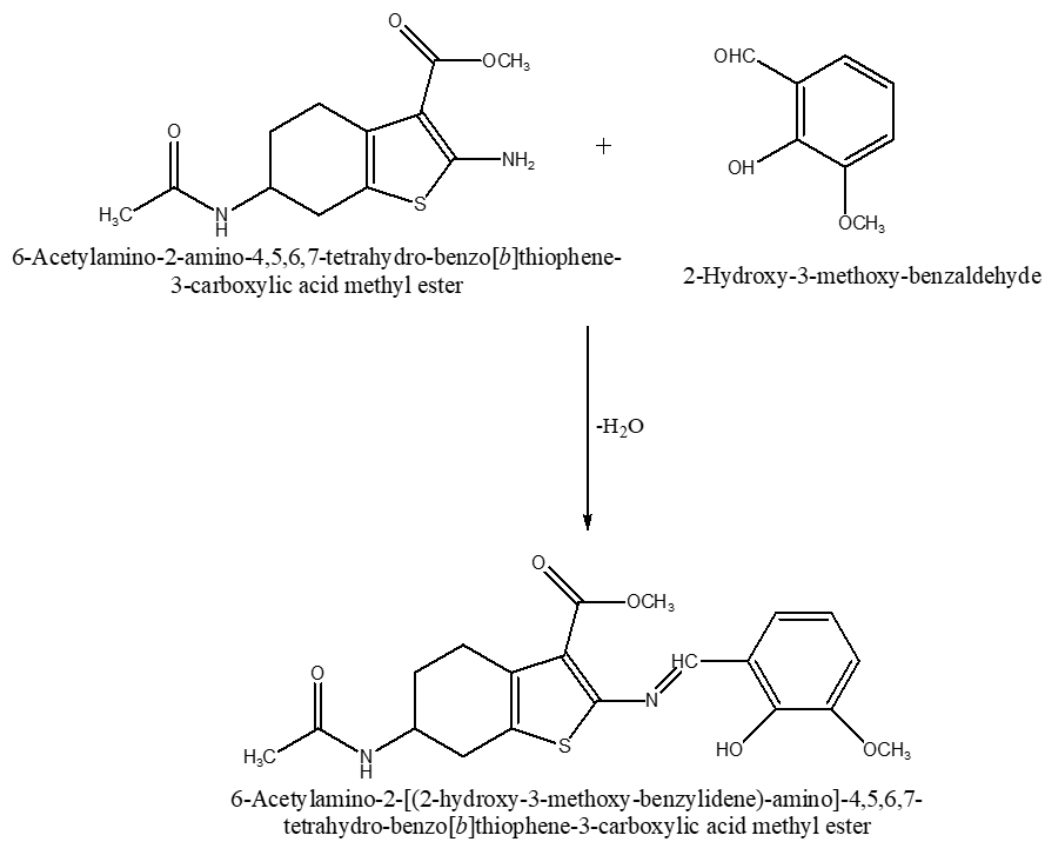

Scheme 13. Synthesis of the Schiff base ligand.
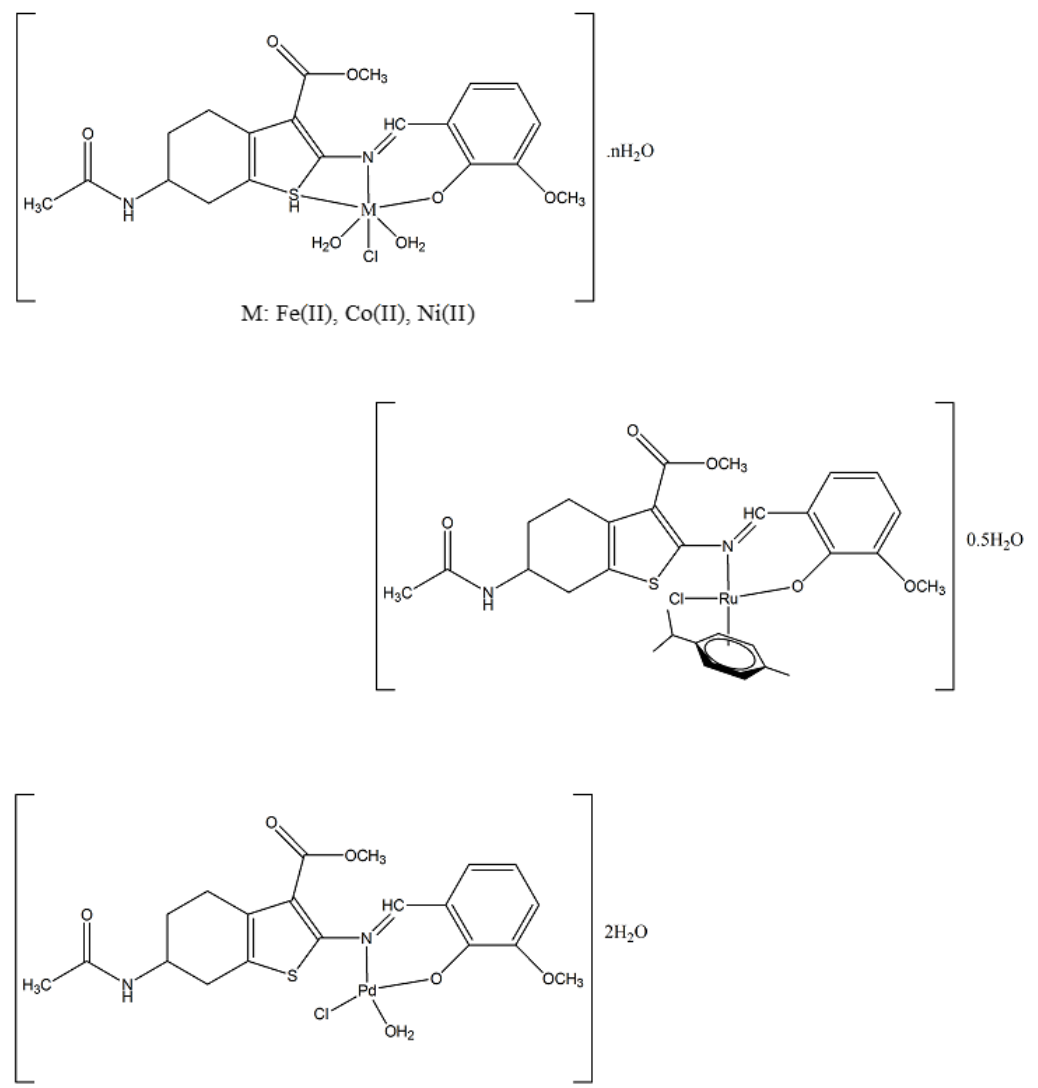

Scheme 14. Proposed structure of the metal(II) complexes.

Horozić et al. synthesized a new Schiff base, 2-(1,3-dioxo-indan-2-ylideneamino)-3( $H$-indol-3-yl)-propionic acid from the condensation of tryptophan (essential amino acid) and 2,2-dihydroxyindane-1,3-dione. The copper (II) complex of the synthesized Schiff base was also synthesized (Scheme 16). 

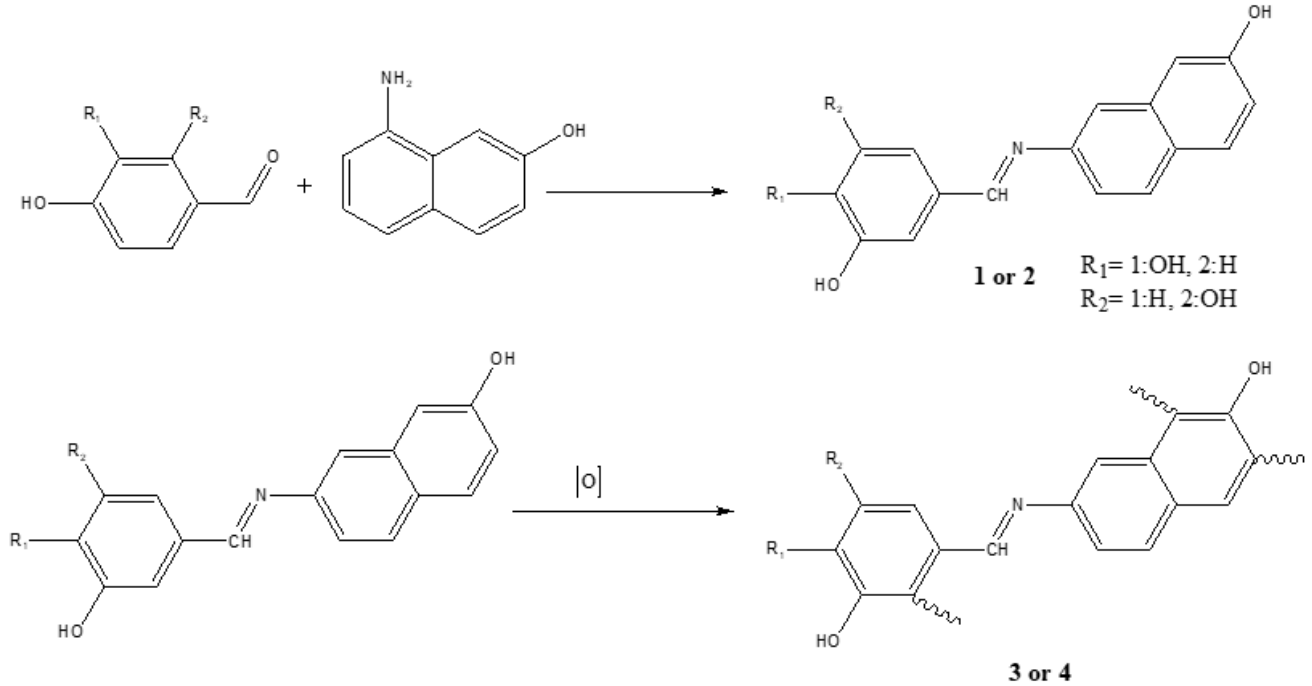

Scheme 15. The general synthetic procedure for 1-4 compounds.

Table 5. $\mathrm{IC}_{50}$ values of the samples.

\begin{tabular}{|c|c|c|c|c|c|}
\hline \multirow{2}{*}{ Sample } & \multicolumn{4}{|c|}{$\mathrm{IC}_{50}(\mu \mathrm{g} / \mathrm{ml})$} & \multirow[b]{2}{*}{ TPC $(\mu \mathrm{gGAE} / \mathrm{g})$} \\
\hline & DPPH & $\mathrm{MC}$ & FRAP & ABTS & \\
\hline 2 & $23.55 \pm 0.20$ & $39.96 \pm 0.91$ & $18.87 \pm 0.18$ & $15.02 \pm 0.01$ & - \\
\hline 4 & $21.28 \pm 0.03$ & $22.81 \pm 0.11$ & $9.99 \pm 0.79$ & $11.34 \pm 0.06$ & $453.56 \pm 5.96$ \\
\hline 1 & $12.71 \pm 0.04$ & $51.70 \pm 0.92$ & $24.95 \pm 0.45$ & $13.23 \pm 0.23$ & - \\
\hline 3 & $10.40 \pm 0.06$ & $43.83 \pm 1.46$ & $8.66 \pm 0.4$ & $6.64 \pm 0.08$ & $672.93 \pm 6.25$ \\
\hline BHT & - & $46.76 \pm 0.39$ & - & - & - \\
\hline Ascorbic acid & $8.08 \pm 0.05$ & - & - & - & - \\
\hline Vitamin E & - & - & $4.44 \pm 0.34$ & $23.16 \pm 0.37$ & - \\
\hline
\end{tabular}

The complex formed was characterized by spectroscopic techniques. DPPH and FRAPS methods were used to study the antioxidant power of the complex. The complex was found to be an effective antioxidant. The $\mathrm{IC}_{50}$ values of the complex and compared with the standard ascorbic acid are given in Table 6 [52].
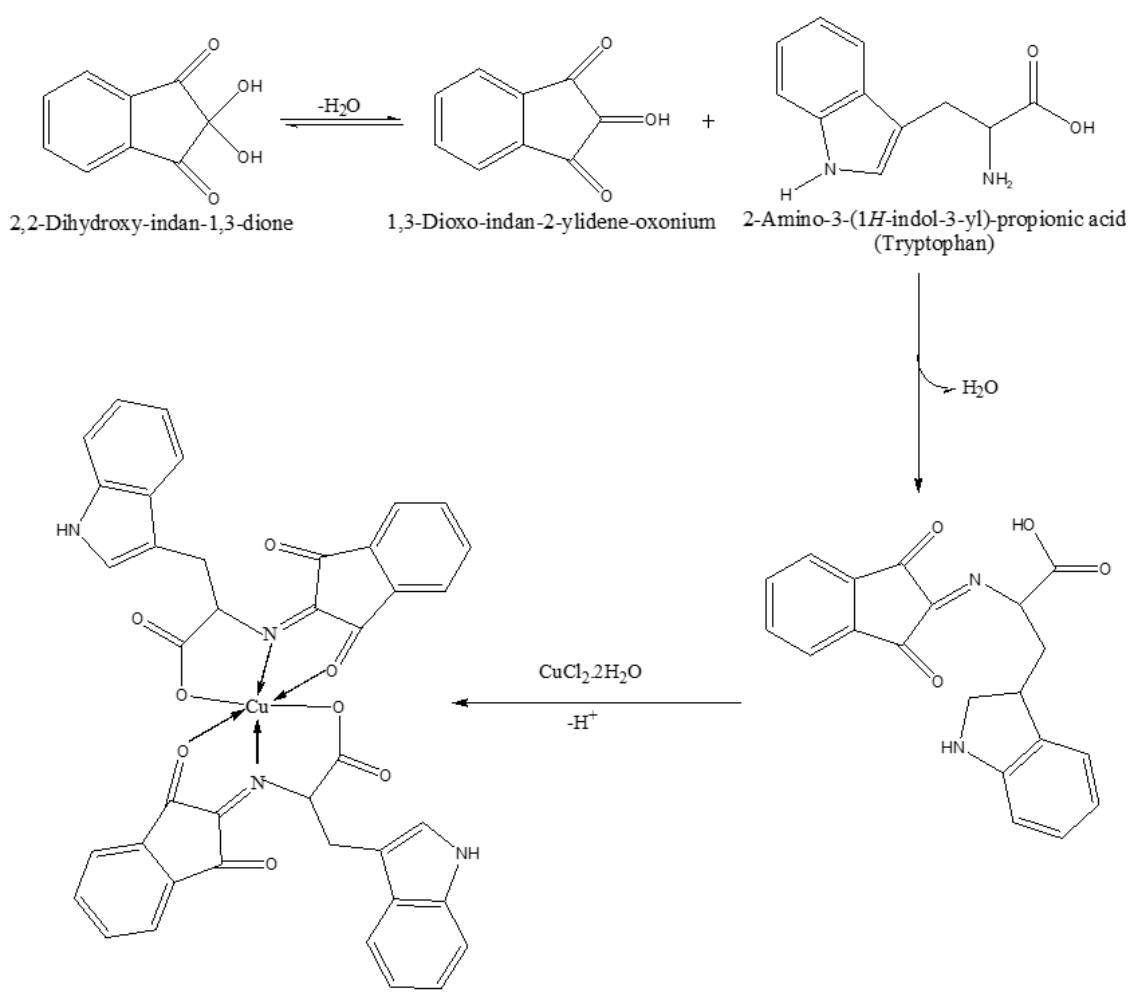

Scheme 16. Reaction for the preparation of the Schiff base and proposed structure of the complex. 
Table 6. Summarized results of antioxidant capacity.

\begin{tabular}{c|c|c}
\hline Sample & DPPH value $\left(\mathbf{m g m L}^{\mathbf{- 1}}\right)$ & FRAP value $\left(\boldsymbol{\mu m o l L}^{-\mathbf{1}}\right)$ \\
\hline $\mathrm{Cu}(\mathrm{II})$ & 0.095 & 587.5 \\
\hline Ascorbic acid & 0.035 & 14.250 \\
\hline
\end{tabular}

Akocak et al. synthesized twenty histamine Schiff bases $(\mathrm{H}(1-20))$ through the reaction of histamine dihydrochloride with different substituted aromatic, heterocyclic, and aliphatic aldehyde derivatives. Spectroscopic techniques and elemental analysis were used to characterize the Schiff bases (Scheme 17). The antioxidant properties of the Schiff bases were determined using DPPH, ABTS, CUPRAC, and metal chelating methods. The standard antioxidants used in DPPH, ABTS and CUPRAC methods were triplicate, BHA, BHT, and $\alpha-$ Toc. While the used in metal chelating method was EDTA. The $\mathrm{IC}_{50}$ values of the synthesized compounds, along with the reference standards, are given in Table $7[53,54]$.
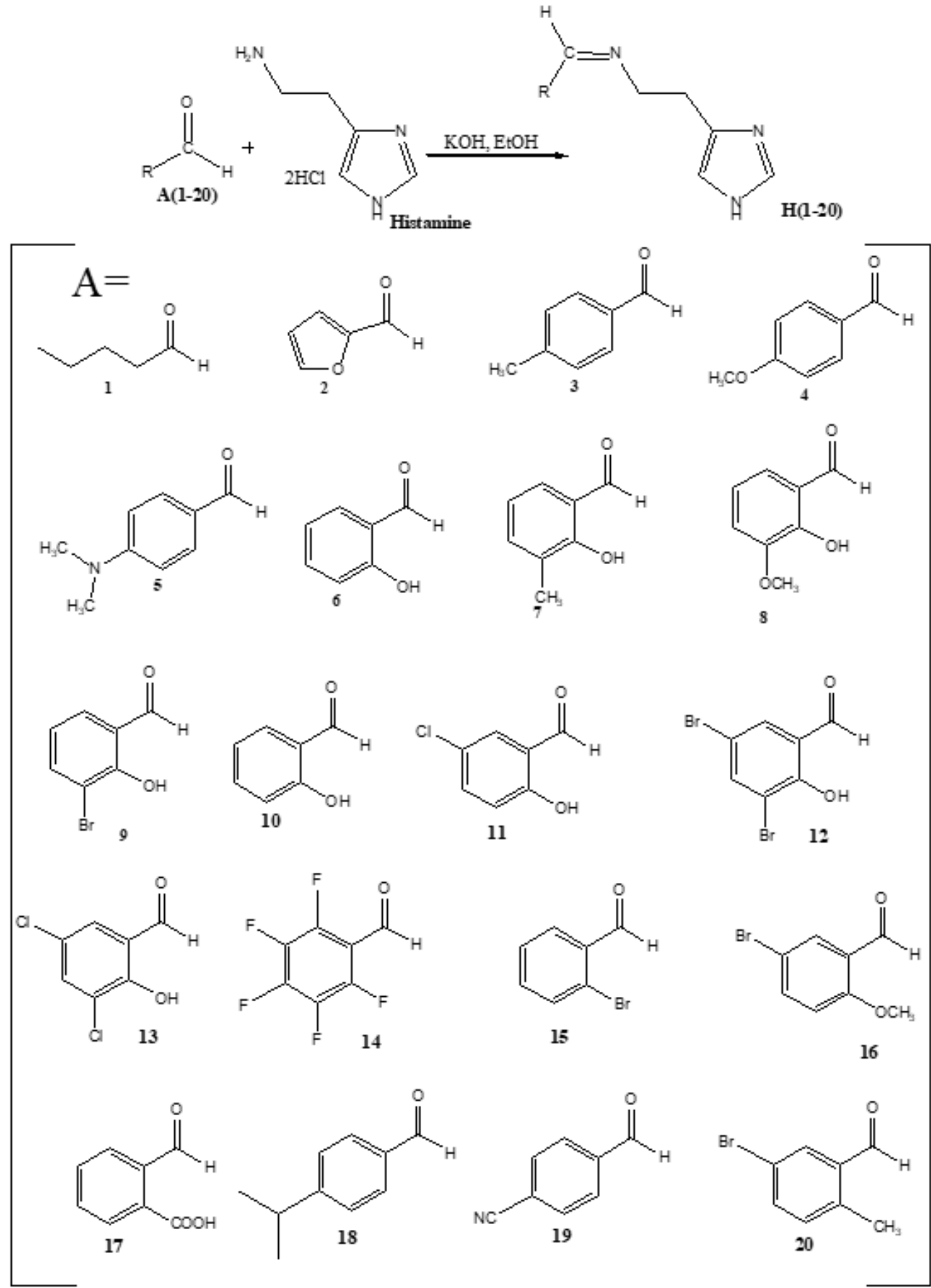

Scheme 17. General synthetic procedure for the synthesis of Schiff bases H(1-20). 
Table 7. IC50 values of Schiff bases H(1-20) and controls BHA, BHT, $\alpha$-Toc, and EDTA.

\begin{tabular}{|c|c|c|c|c|c|}
\hline \multirow[b]{2}{*}{ S. No. } & \multirow[b]{2}{*}{ Comp. } & \multirow[b]{2}{*}{ Alkyl group (R) } & \multicolumn{3}{|c|}{$\operatorname{IC50}(\mu M)^{a}$} \\
\hline & & & $\begin{array}{l}\text { DPPH Free } \\
\text { Radical } \\
\text { Scavenging } \\
\text { Activity }\end{array}$ & $\begin{array}{c}\text { ABTS Cation } \\
\text { Radical Scavenging } \\
\text { Activity }\end{array}$ & $\begin{array}{c}\text { Metal } \\
\text { Chelating } \\
\text { Activity }\end{array}$ \\
\hline 1 & H1 & -Valeryl & $428.41 \pm 1.33$ & $>1000$ & $125.45 \pm 1.43$ \\
\hline 2 & $\mathrm{H} 2$ & -Furyl & $471.66 \pm 0.79$ & $593.67 \pm 1.16$ & $150.38 \pm 0.97$ \\
\hline 3 & $\mathrm{H} 3$ & -4-Me-Phenyl & $685.68 \pm 1.01$ & $>1000$ & $101.38 \pm 0.80$ \\
\hline 4 & $\mathrm{H} 4$ & -4-MeO-Phenyl & $368.16 \pm 1.57$ & $585.67 \pm 1.16$ & $147.31 \pm 0.97$ \\
\hline 5 & $\mathrm{H} 5$ & -4-N(Me) $)_{2}$-Phenyl & $581.67 \pm 0.59$ & $601.07 \pm 0.96$ & $200.58 \pm 0.87$ \\
\hline 6 & H6 & -2-OH-Phenyl & $630.43 \pm 1.39$ & $255.71 \pm 0.39$ & $296.25 \pm 0.63$ \\
\hline 7 & $\mathrm{H} 7$ & -2-OH-3Me-Phenyl & $623.83 \pm 1.45$ & $>1000$ & $203.37 \pm 1.12$ \\
\hline 8 & $\mathrm{H} 8$ & -2-OH-3MeO-Phenyl & $249.63 \pm 0.28$ & $220.92 \pm 1.11$ & $116.62 \pm 1.28$ \\
\hline 9 & $\mathrm{H} 9$ & -2-OH-3Br-Phenyl & $832.41 \pm 1.43$ & $89.18 \pm 0.02$ & $82.33 \pm 0.58$ \\
\hline 10 & $\mathrm{H} 10$ & -2-OH-5Br-Phenyl & $858.21 \pm 1.67$ & $448.01 \pm 1.02$ & $115.66 \pm 1.28$ \\
\hline 11 & H11 & -2-OH-5Cl-Phenyl & $389.76 \pm 1.29$ & $511.38 \pm 1.01$ & $86.65 \pm 1.11$ \\
\hline 12 & H12 & -2-OH-3,5-diBr-Phenyl & $472.79 \pm 0.87$ & $129.24 \pm 0.32$ & $219.34 \pm 1.05$ \\
\hline 13 & H13 & -2-OH-3,5-diCl-Phenyl & $541.52 \pm 0.89$ & $577.82 \pm 0.51$ & $127.59 \pm 0.85$ \\
\hline 14 & H14 & $\begin{array}{c}-2,3,4,5,6-\text { PentaF- } \\
\text { Phenyl }\end{array}$ & $>1000$ & $749.89 \pm 1.57$ & $209.31 \pm 0.44$ \\
\hline 15 & H15 & -2-Br-Phenyl & $539.42 \pm 1.28$ & $868.89 \pm 1.88$ & $146.53 \pm 0.27$ \\
\hline 16 & H16 & -2-MeO-5-Br-Phenyl & $625.23 \pm 1.26$ & $123.23 \pm 0.63$ & $70.34 \pm 0.81$ \\
\hline 17 & H17 & -2-COOH-Phenyl & $579.42 \pm 0.89$ & $508.46 \pm 0.57$ & $110.26 \pm 0.98$ \\
\hline 18 & $\mathrm{H} 18$ & -4-iPr-Phenyl & $945.23 \pm 0.75$ & $>1000$ & $132.22 \pm 0.92$ \\
\hline 19 & H19 & -4-CN-Phenyl & $846 \pm 0.96$ & $>1000$ & $208.38 \pm 0.86$ \\
\hline 20 & $\mathrm{H} 20$ & -2-Me-5-Br-Phenyl & $631.17 \pm 1.43$ & $127.99 \pm 0.65$ & $183.09 \pm 0.21$ \\
\hline 21 & $\mathrm{BHA}^{\mathrm{b}}$ & - & $61.72 \pm 0.85$ & $45.40 \pm 1.08$ & - \\
\hline 22 & $\mathrm{BHT}^{\mathrm{b}}$ & - & $232.11 \pm 3.01$ & $26.54 \pm 0.18$ & - \\
\hline 23 & $\alpha-$ TOC $^{b}$ & - & $56.86 \pm 0.77$ & $34.12 \pm 0.41$ & - \\
\hline 24 & EDTA $^{b}$ & - & - & - & $52.35 \pm 1.15$ \\
\hline
\end{tabular}<smiles>[Y]c1ccc(O)c(C(=O)O)c1</smiles>

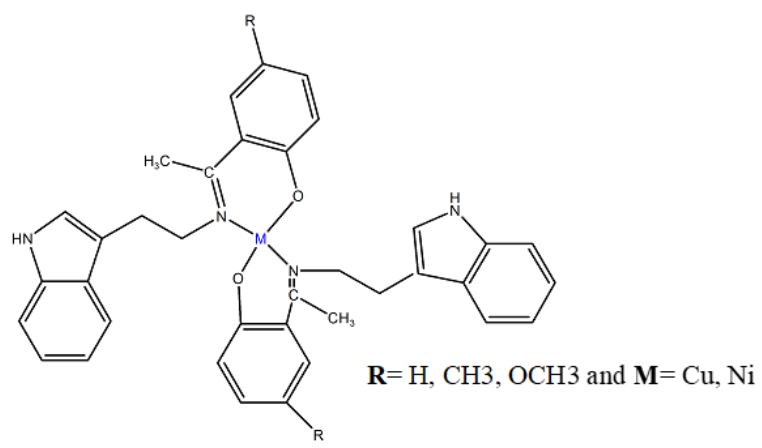

Scheme 18. General synthesis of the Schiff base ligands and Proposed structure of $\mathrm{Cu}(\mathrm{II})$ and $\mathrm{Ni}(\mathrm{II})$ complexes.

Alomari et al., synthesized three Schiff base ligands: 2-\{1-[2-(1H-indole-3yl)ethylimino]-ethyl $\}$ phenol $\quad$ (THAP), 2-\{1-[2-(1H-indole-3-yl)ethylimino]-ethyl $\}-4-$ methylphenol (TMeHAP), 2-\{1-[2-(1H-indole-3-yl)ethylimino]-ethyl $\}$-4-methoxyphenol (TOMeHAP) by the condensation reaction of tryptamine and 1-(2-hydoxy-phenyl)-ethanone, 1-(2-hydroxy-5-methyl-phenyl)-ethanone and 1-(2-hdroxy-5-methoxy-phenyl)-ethanone. They also synthesized their $\mathrm{Cu}$ (II) and $\mathrm{Ni}(\mathrm{II})$ complexes (Scheme 18). All the synthesized compounds were characterized by infrared spectroscopy, ${ }^{13} \mathrm{CNMR},{ }^{1} \mathrm{HNMR}$, UV-visible spectroscopy, elemental analysis, and magnetic measurements. $\left[\mathrm{M}(\mathrm{L})_{2}\right]$ was presented as the general formula for the complexes, which indicates that the Schiff bases are bidentate ligands and azomethine nitrogen atom and deprotonated phenolate oxygen coordinate to the metal 
atoms. DPPH and FRAP methods were used to study the antioxidant properties of the compounds in which BHT was used as a standard. The results showed that the Schiff bases were more effective antioxidants as compared to the metal complexes [55].

The synthesis of nine Schiff bases has been reported by the condensation reaction of various primary aromatic diamines and hydroxylbenzaldehyde using Stannous Chloride $(\mathrm{SnCl} 2 \cdot 2 \mathrm{H} 2 \mathrm{O})$ as the catalyst (Table 8$)$. The products formed were characterized by Gas chromatography-mass spectrometry (GCMS), NMR spectroscopy, and FT-IR spectroscopy. The compounds were tested for antioxidant activities using DPPH assay, and ABTS assay and the $\mathrm{IC}_{50}$ values were compared with the parent aldehyde as well as with a standard compound, Trolox. These compounds showed significant antioxidant activities because these compounds are substituted with the phenolic OH groups. IC50 values of the synthesized compounds in DPPH free radical scavenging assay decreased in the following order: $1>5>6>4>2>8>7>3>9$ while the $\mathrm{IC}_{50}$ values of the compounds in ABTS radical scavenging assay decreased in the following order: $1>5>4>6>2>8>7>3>9$. Since smaller, the $\mathrm{IC}_{50}$ value greater will be the antioxidant activity of the compound. So compound 9 showed greater antioxidant activity as compared to the other synthesized compounds. However, the synthesized compounds showed better antioxidant activity than their corresponding parent aldehydes [56].

Table 8. Scheme of synthesis of nine Schiff bases.

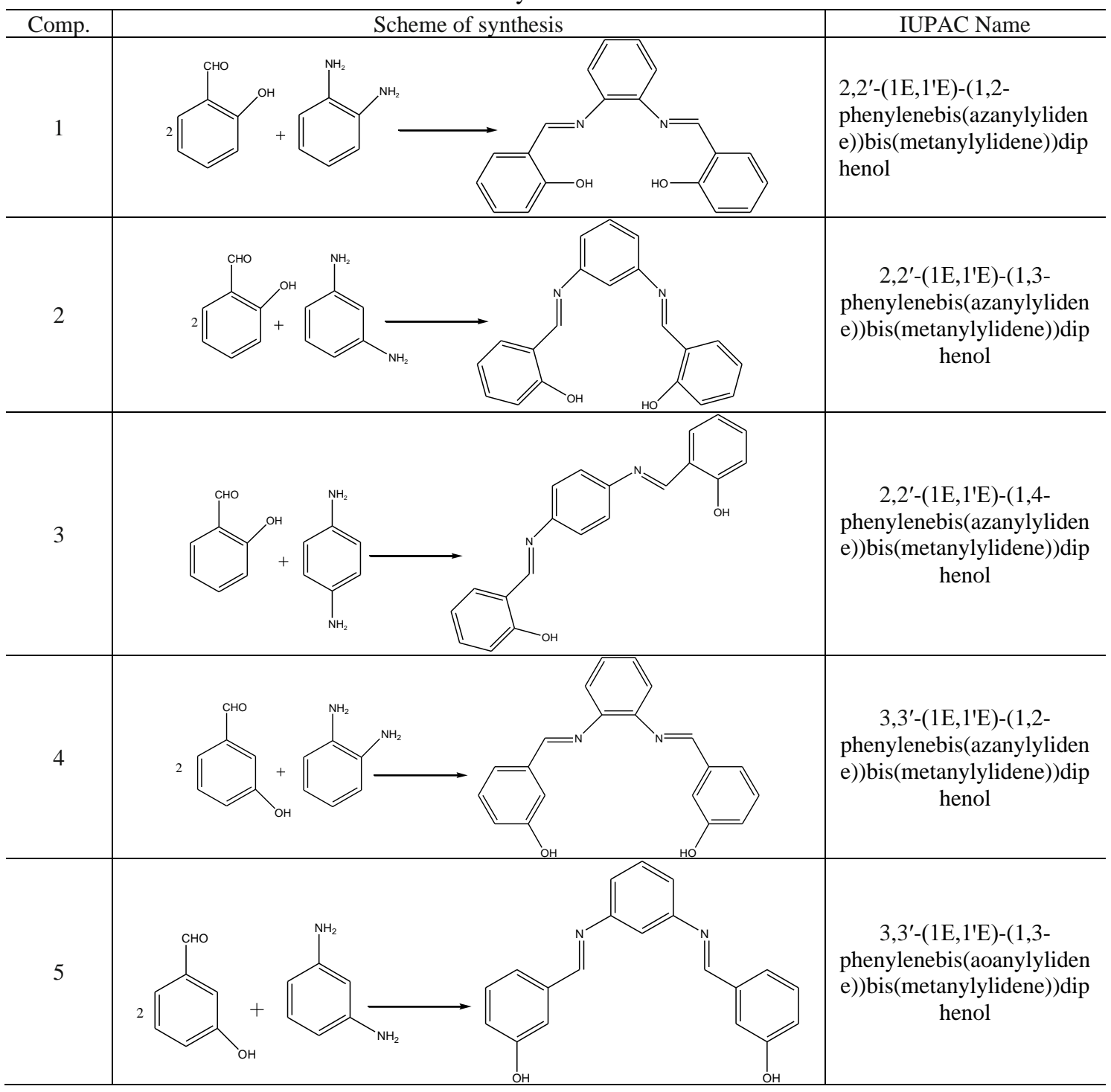




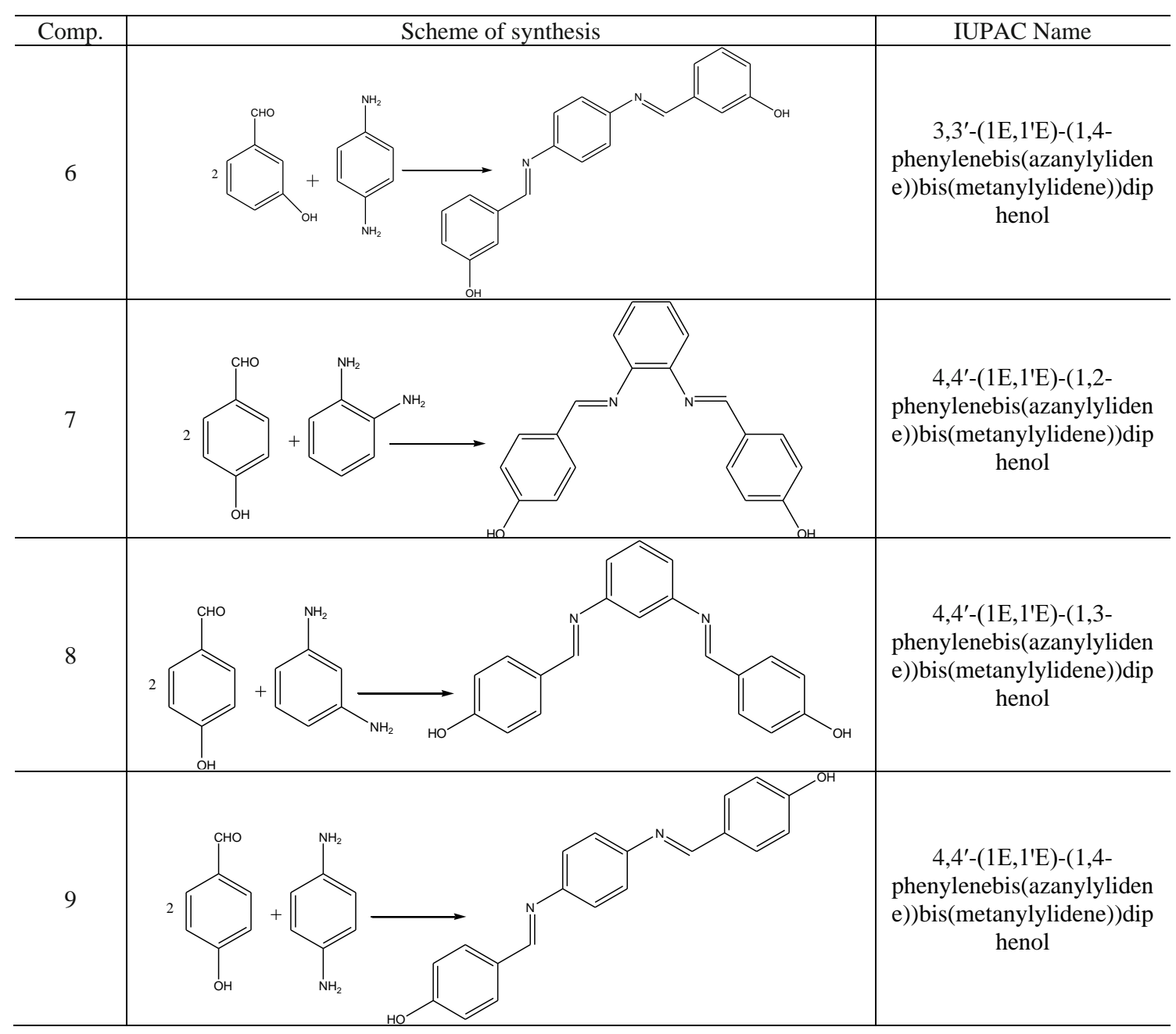

Three Isatin Schiff bases: 2-(2-oxoindolin-3-ylamino)-5-phenyl-1,3,4-thiadiazole (I), 3-(4-(ethyl benzoate)imino)indolin-2-one (II), 2-(2-oxoindolin-3-ylamino)-5-mercapto-1,3,4thiadiazole (III), have been reported. Synthesized via the reaction of isatin with various amines (Scheme 19). The synthesized Isatins were characterized by FT-IR spectroscopy and ${ }^{1} \mathrm{HNMR}$ spectroscopy. Isatin Schiff bases have important medicinal applications because of their structurally motivating antioxidant activities. The antioxidant properties of Isatin-azomethines were evaluated using DPPH, FRAP, and Ferrous ions chelating activity assays. The IC50 values of the compounds were compared with that of ascorbic acid. The synthesized compounds had the capability of complexation with Iron. It was observed that the synthesized compounds showed better antioxidant activities as compared to ascorbic acid [57].

A new Schiff base ligand: 2-[(Furan-2ylmethyllene)-amino]-phenol synthesized from 2-Furan carboxaldehyde and o-aminophenol, and its $\mathrm{Cu}$ (II) complex (Scheme 20) were reported by Shakila et al. The synthesized Schiff bases and complexes were characterized by ultraviolet-visible spectroscopy, FT-IR, ${ }^{1} \mathrm{HNMR},{ }^{13} \mathrm{CNMR}$, and Electron spin resonance spectroscopy. The free radical scavenging activity of the compounds was studied at different concentrations in DPPH solution using ascorbic acid as a standard antioxidant. The compounds showed noteworthy antioxidant power, but the complex was better antioxidant than the corresponding ligand due to the complexation of the ligand with copper(II) ion [58].

Oloyede-Akinsulere et al. synthesized Five substituted tridentate salicylaldimines, (E)2-((2-hydroxybenzylidene)amino)phenol (1), (E)-2-(((2-hydroxyphenyl)imino)methyl)-4nitrophenol (2), (E)-4-chloro-2-(((2-hydroxyphenyl)imino)methyl)phenol (3), (E)-2-(((2hydroxyphenyl)imino)methyl)-4-methoxyphenol (4), (E)-4-bromo-2-(((2-hydroxyphenyl) 
imino)methyl)-6-methoxyphenol (5) from corresponding substituted salicylaldehydes and $o$ aminophenol (Scheme 21).

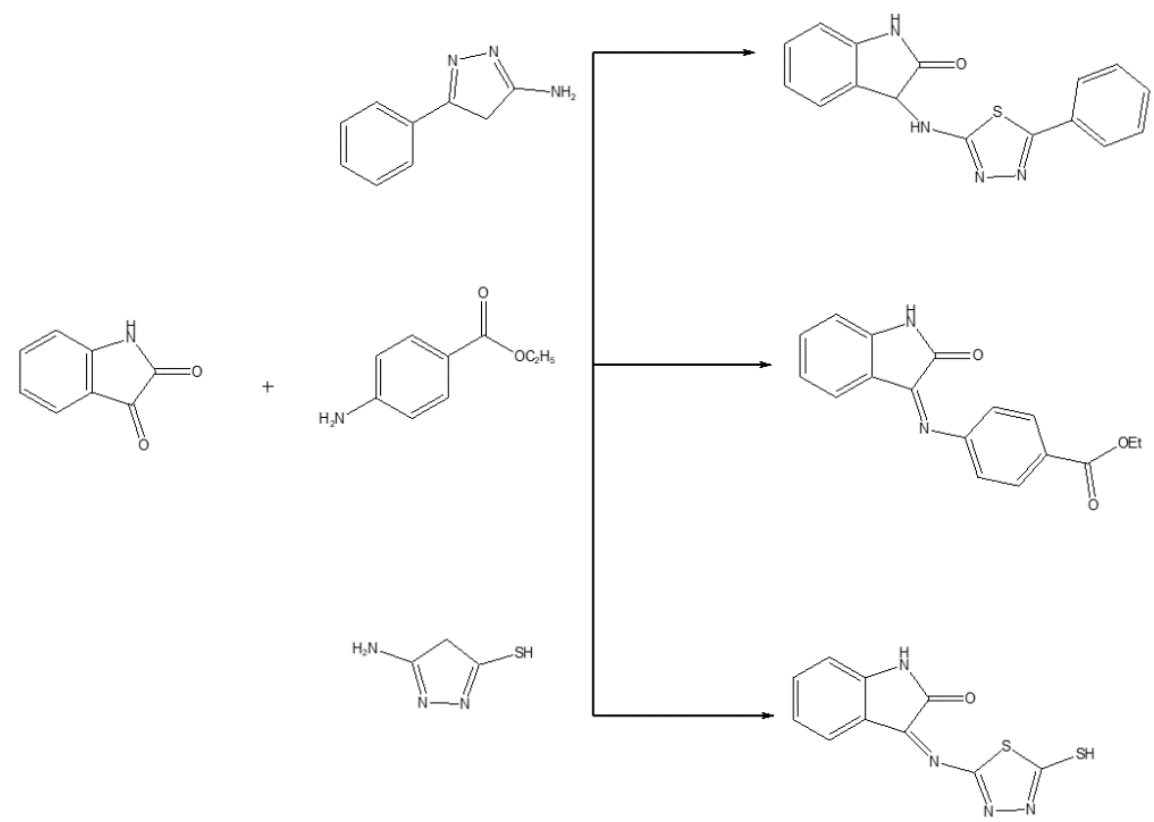

Scheme 19. Chemical structures of the prepared compounds 1-3.
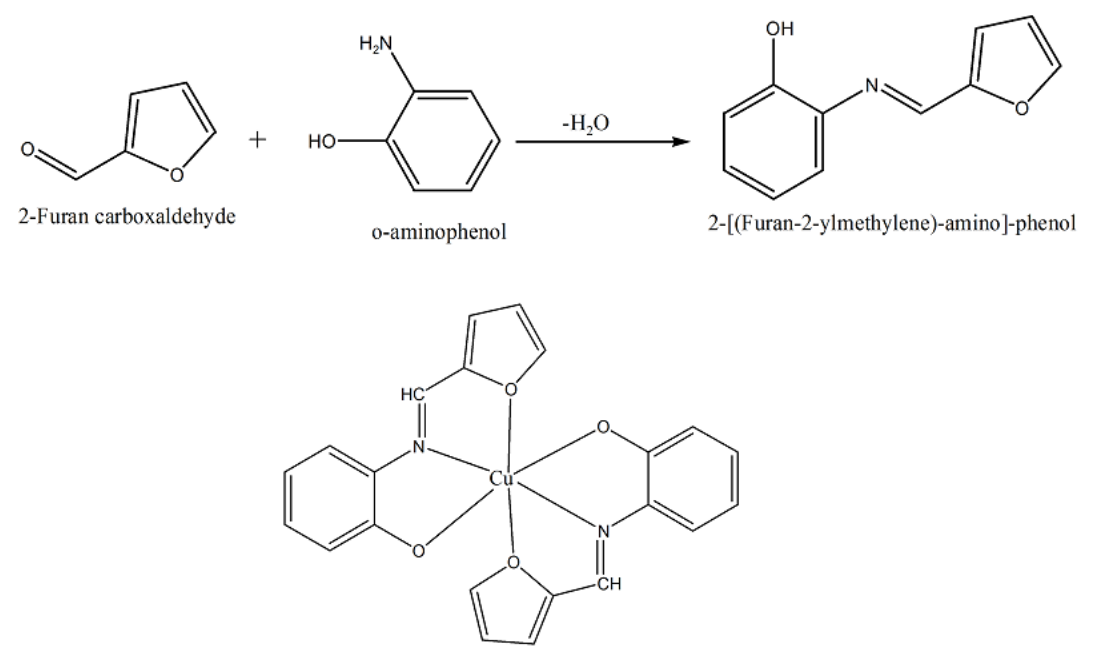

Scheme 20. Reaction for the synthesis of Schiff base and structure of the $\mathrm{Cu}(\mathrm{II})$ complex.

Spectroscopic techniques and elemental analysis were used to characterize the compounds. Their antibacterial capacities were determined by screening the compounds against Grampositive and Gram-negative organisms, including Staphylococcus aureus and Escherichia coli etc. While their antioxidant activities were determined by the Phosphomolybdate Total Antioxidant Capacity (PTAC) Assay. From the results, it was clear that the nitro-substituted compounds exhibited the least antioxidant and antibacterial activities. In contrast, the methoxy-substituted compound exhibited the highest antibacterial and antioxidant activities. The compound 4 was found to have better free radical scavenging capacity [59].

The $\mathrm{Cu}(\mathrm{II}), \mathrm{Cr}(\mathrm{III}), \mathrm{Cd}(\mathrm{II}), \mathrm{Zn}(\mathrm{II})$, and VO(II) complexes of the Schiff base ligand: 2(((4-(1-((4-bromophenyl) imino)ethyl) phenyl)imino)methyl)phenol, synthesized by the reaction of P-aminoacetophenone with salicylaldehyde and P-bromoaniline, have been reported (Scheme 22). The characterization of the compounds was performed using different 
methods, including ultraviolet-visible spectroscopy, mass spectroscopy, elemental microanalysis, Fourier transform infrared, thermal gravimetric analysis, flame atomic absorption and molar conductivity.

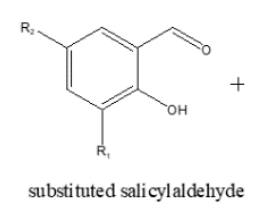

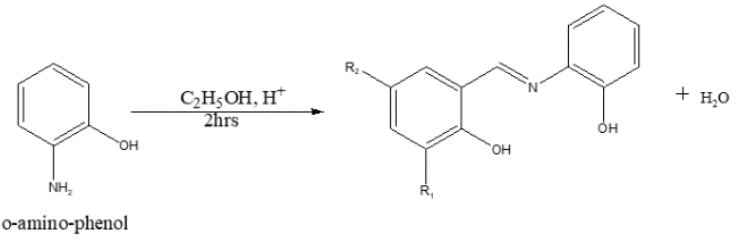

$$
\begin{aligned}
& 1-\mathrm{R}_{1}=\mathrm{R}_{2}=\mathrm{H} \\
& 2-\mathrm{R}_{1}=\mathrm{H}, \mathrm{R}_{2}=\mathrm{NO}_{2} \\
& 3-\mathrm{R}_{1}=\mathrm{H}, \mathrm{R}_{2}=\mathrm{Cl} \\
& 4-\mathrm{R}_{1}=\mathrm{H}, \mathrm{R}_{2}=\mathrm{OCH}_{3} \\
& 5-\mathrm{R}_{1}=\mathrm{OCH}_{3}, \mathrm{R}_{2}=\mathrm{Br}
\end{aligned}
$$

Scheme 21. General synthetic procedure for the synthesis of compounds 1-5.

It was suggested from the results that all the complexes have octahedral geometry except Compound 5, which was pyramidal and all the complexes were found to be nonelectrolytes. The compounds were found to have better anticancer and antioxidant properties. The anticancer activities of the complexes were determined by screening them against breast cancer cells (MCF-7), brain cancer cells (AMJM), cervical cancer cells (HeLa), and ovarian cancer cells (SKOV-3). Using DPPH method, the antioxidant power of the Schiff base and complexes was studied. The results revealed that the complexes are better antioxidant than ligand. However, among the complexes, the $\mathrm{Cu}(\mathrm{II})$ complex showed enhanced antioxidant activity [60].
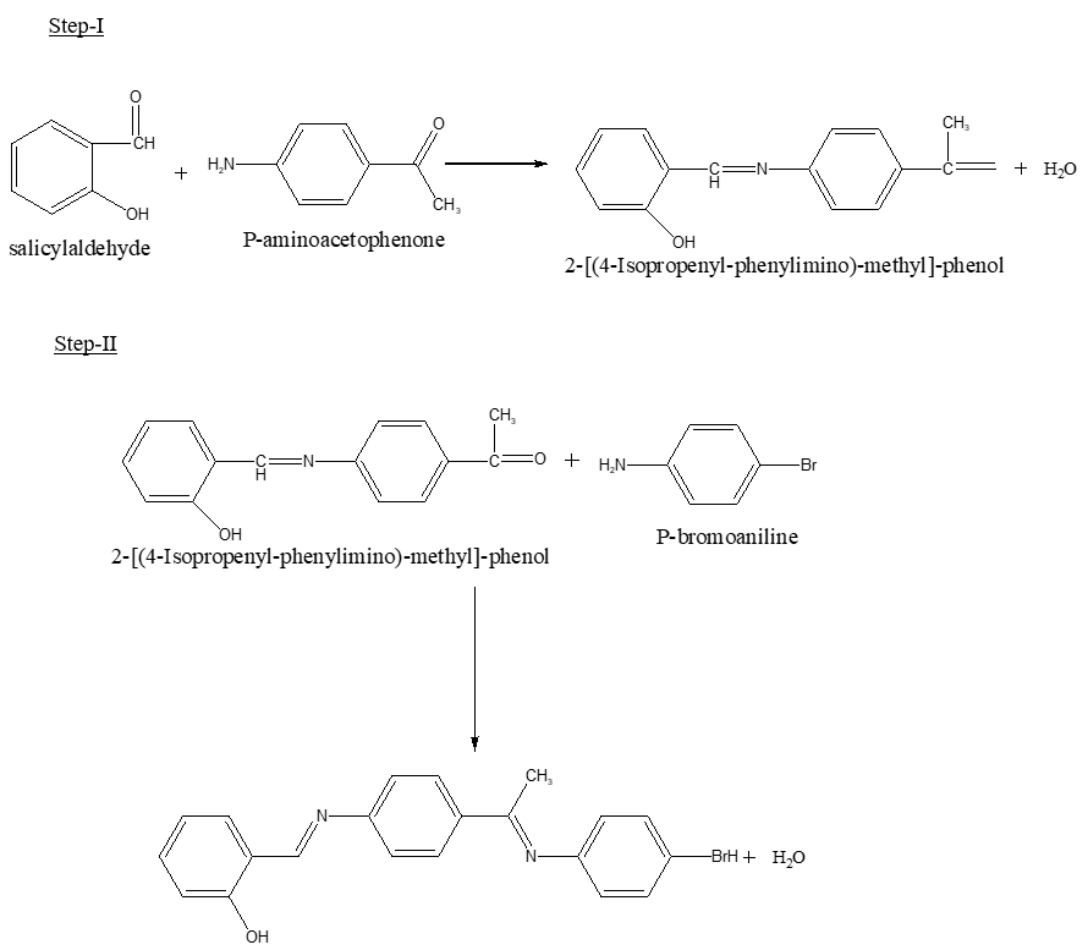

Scheme 22. Reaction for the preparation of Schiff base.

The synthesis of a new chromone-functionalized chitosan Schiff base $(\mathrm{CSCH})$ from the condensation reaction of 6-formyl-7-hydroxy-5-methoxy-2-methylbenzopyran-4-one $(\mathrm{CH})$ and chitosan (CS) and its cross-linked derivative (CSCH-TP) from the reaction of CSCH and terephthalaldehyde (TP) have been reported (Scheme 23). The products formed were characterized by FT-IR spectroscopy, UV-Visible spectroscopy, ${ }^{13} \mathrm{C}-\mathrm{NMR}$, scanning electron 
microscopy (SEM), thermal analysis, elemental analysis, and X-ray diffraction (XRD). The antioxidant properties of the synthesized compounds were evaluated against DPPH radicals. The result showed that the chromone-chitosan Schiff base ( $\mathrm{CSCH})$ had higher antioxidant activity as compared to its cross-linked derivative, while both of the chitosan chromone derivatives showed better scavenging activity as compared to the original chitosan [61].

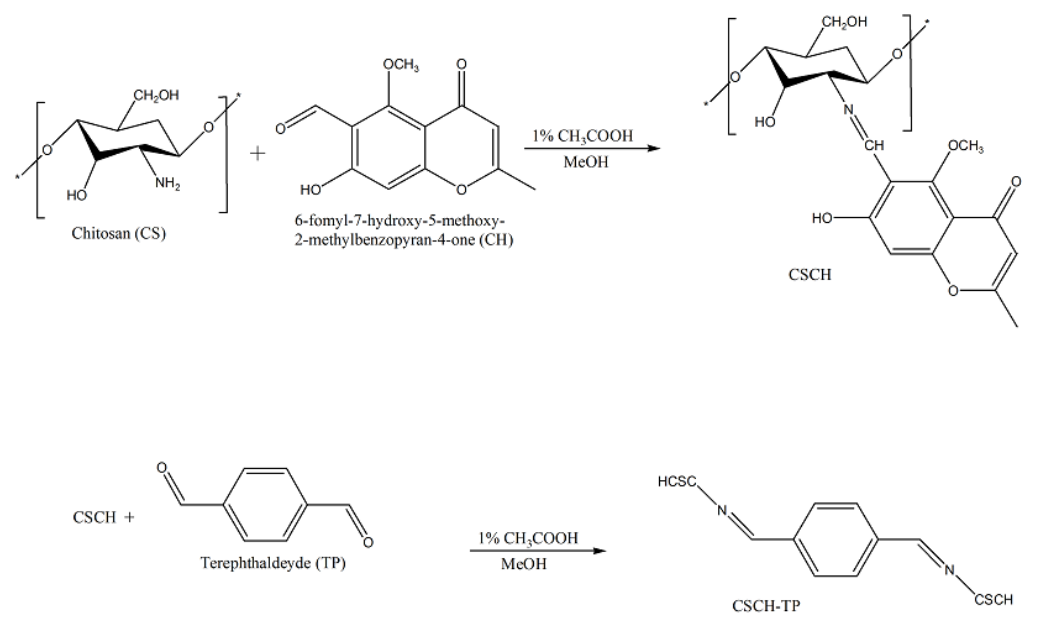

Scheme 23. Synthesis of $\mathrm{CHCH}$ and $\mathrm{CSCH}-\mathrm{TP}$.

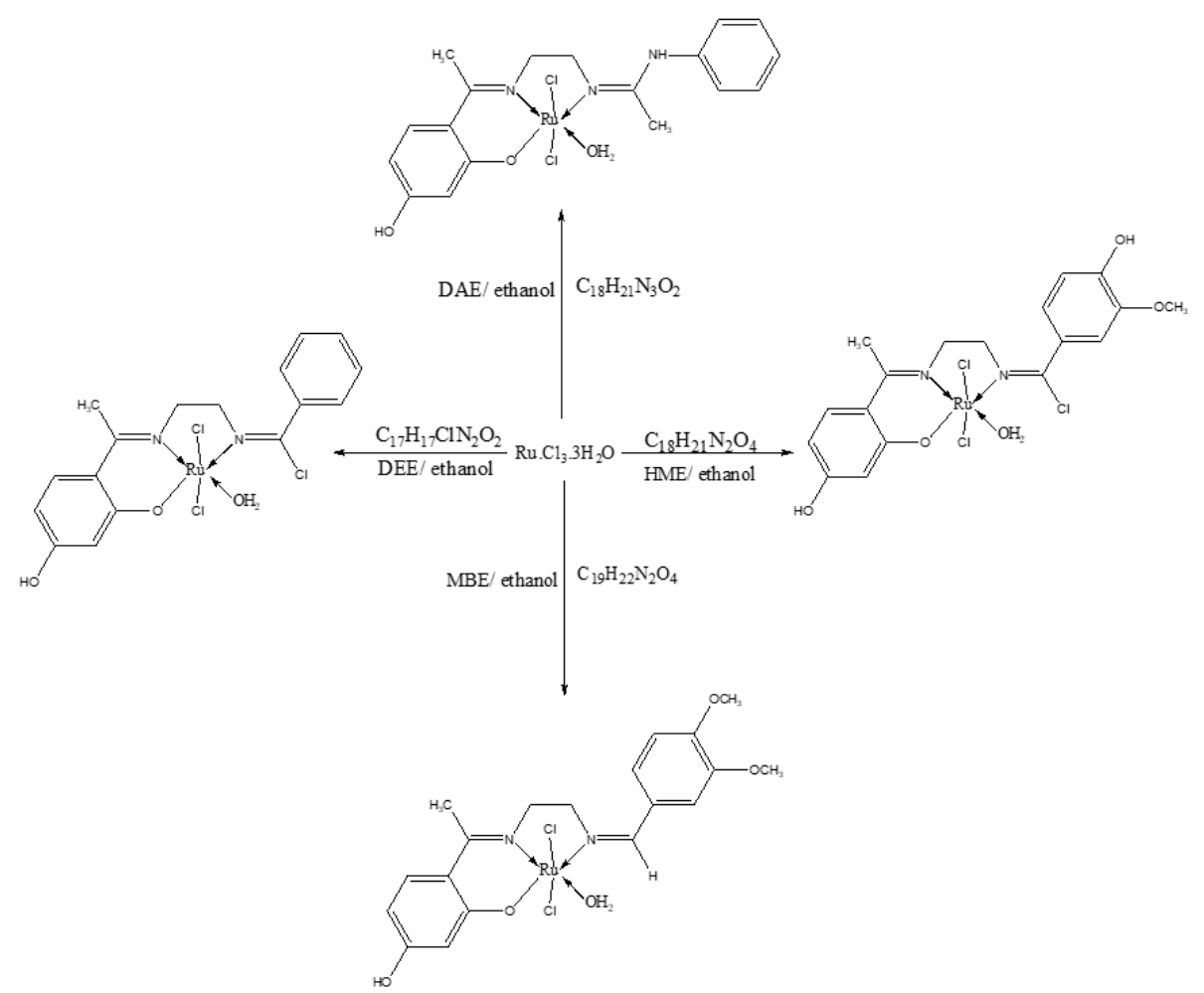

Scheme 24. Structure of mononuclear Ruthenium(III)-Schiff base complexes.

Tridentate Schiff bases namely (1Z)- $N^{\prime}-(2-\{(E)-[1-(2,4-$ dihydroxyphenyl)ethylidene] amino $\}$ ethyl)- $N$-phenylethanimidamide $\quad$ (DAE), 4-[(1E)- $N-\{2-[(Z)-(4-h y d r o x y-3-$ metoxybenzylidene)amino]ethyl $\}$ ethanimidoyl]benzene-1,3-diol (HME), 4-[(1E)- $N$ - $\{2-[(Z)-$ (3,4-dimethoxybenzylidene)amino] ethyl \}ethanimidoyl]benzene-1,3-diol (MBE) and $N$-(2$\{(E)$-[1-(2,4-dihydroxyphenyl)ethylidene]amino\}ethyl)benzenecarboximidoyl chloride (DEE) and their $\mathrm{Ru}(\mathrm{III})$ complexes of the type $\left[\mathrm{Ru}(\mathrm{LL}) \mathrm{Cl}_{2}\left(\mathrm{H}_{2} \mathrm{O}\right)\right]$ ( $\mathrm{LL}=\mathrm{DAE}, \mathrm{HME}, \mathrm{MBE}$ and DEE) have been reported (Scheme 24). The products were characterized by FT-IR spectroscopy, electronic spectra, conductivity measurements, and microanalytical techniques. The ligands 
were confirmed to be tridentate from the IR spectral studies. The complexes had better anticancer and antioxidant activities. The anticancer properties of the synthesized complexes were evaluated against breast cancer cells (MCF-7), renal cancer cells (TK-10), and melanoma cancer cells (UACC-62). The complex [Ru(DAE)Cl2(H2O)] showed the highest anticancer activity. ABTS and DPPH methods were used to study the antioxidant power of the complexes. The complex of DEE ligand was found to have higher antioxidant higher radical scavenging capacity in both assays [62].

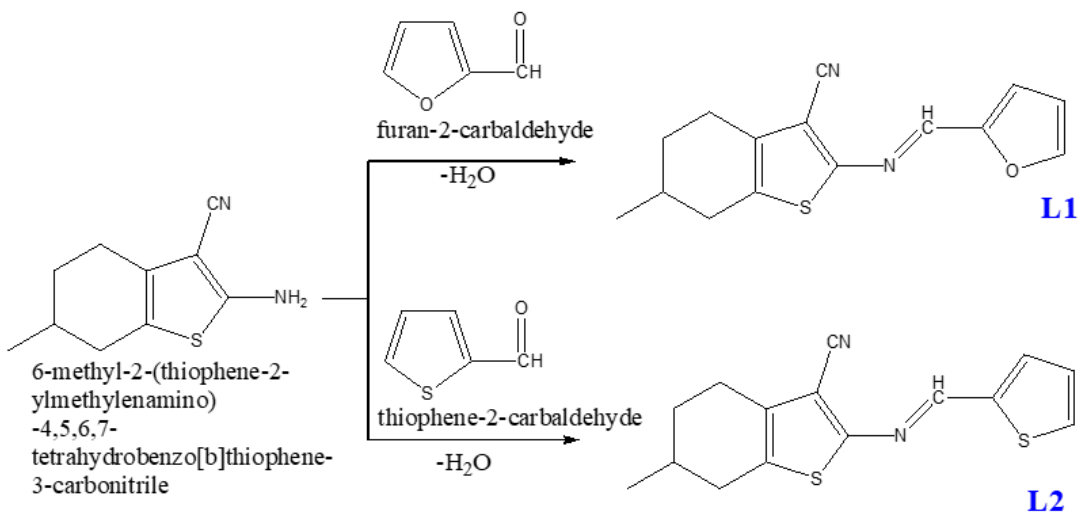

Scheme 25. Reaction for the synthesis of the ligands L1 and L2.

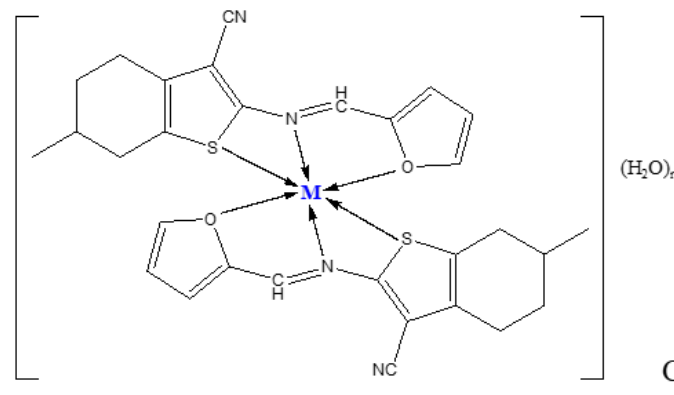

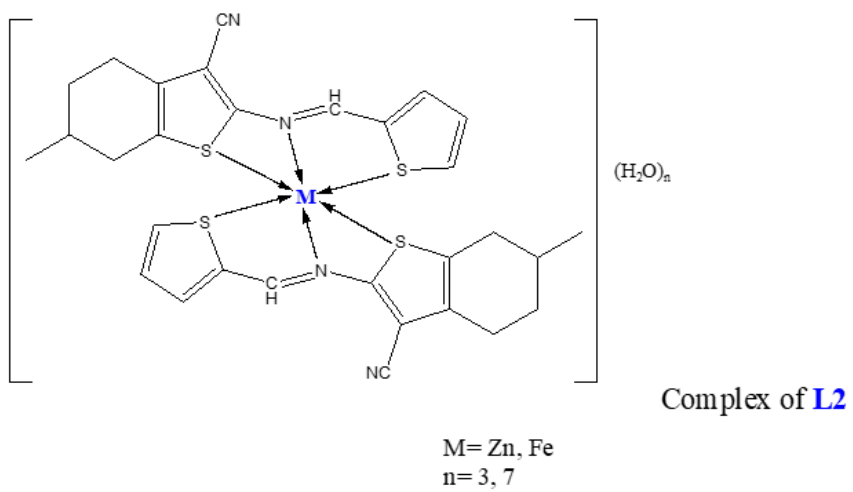

Scheme 26. Proposed structure of the complexes.

Turan et al. synthesized two Schiff base ligands: 2-(furan-2-ylmethylenamino)-6methyl-4,5,6,7-tetrahydrobenzo[b]thiophene-3-carbonitrile (L1) and 6-methyl-2-(thiophene-2ylmethylenamino)4,5,6,7-tetrahydrobenzo[b]thiophene-3-carbonitrile (L2) from the condensation reaction of 2-amino-6-methyl-4,5,6,7-tetrahydrobenzo[b]thiophene-3carbonitrile, furan-2-carbaldehyde and thiophene-2-carbaldehyde (Scheme 25). They also synthesized their $\mathrm{Zn}$ (II) and Fe(II) complexes (Scheme 26). UV-Visible spectroscopy, infrared spectroscopy, ${ }^{1} \mathrm{H}-\mathrm{NMR}$ and ${ }^{13} \mathrm{C}-\mathrm{NMR}$ spectroscopy, thermal analysis, the elemental analysis 
was used for the characterization of the compounds. After different analyses, the following general formulas were suggested for the complexes, $\left.\mathrm{M}(\mathrm{L} 1)_{2}\right]\left(\mathrm{H}_{2} \mathrm{O}\right)_{\mathrm{n}},\left[\mathrm{M}(\mathrm{L} 2)_{2}\right]\left(\mathrm{H}_{2} \mathrm{O}\right)_{\mathrm{n}}$, where $\mathrm{M}=\mathrm{Zn}(\mathrm{II})$ and $\mathrm{Fe}(\mathrm{II})$. Octahedral geometry was suggested for both the complexes. All the compounds were tested for their antibacterial and antioxidant activities. ABTS and FRAP methods were used to test the antioxidant activities of the compounds. It was found that these complexes have better free radical scavenging activities [63].

Al Zoubi et $a$. synthesized a phosphorus-based Schiff base: bis-\{3-[2-(4-amino-1,5dimethyl-2-phenyl-pyrazol-3-ylideneamino)ethyl]-5-methyl-indol-1-ylmethyl $\}$-phosphinic acid (L) by the condensation reaction of 1.5-dimethyl-2-phenyl-3-(5-methyl-1H-indol-3-ylethylimino)-pyrazol-4-ylamine, hypophosphorous acid and paraformaldehyde (Scheme 27) and its corresponding complexes: [(VO) $\left.)_{2} \mathrm{~L}\left(\mathrm{SO}_{4}\right)_{2}\right],\left[\mathrm{Ni}_{2} \mathrm{LCl}_{4}\right], \quad\left[\mathrm{Co}_{2} \mathrm{LCl}_{4}\right], \quad\left[\mathrm{Cu}_{2} \mathrm{LCl}_{4}\right]$, $\left[\mathrm{Zn}_{2} \mathrm{LCl}_{4}\right],\left[\mathrm{Cd}_{2} \mathrm{LCl}_{4}\right],\left[\mathrm{Hg}_{2} \mathrm{LCl}_{4}\right],\left[\mathrm{Pd}_{2} \mathrm{LCl}_{4}\right]$, and $[\mathrm{PtLCl}] \mathrm{Cl}_{2}$ (Scheme 28), characterized by mass spectroscopy, FT-IR spectroscopy, UV-Visible spectroscopy, ${ }^{1} \mathrm{H}-\mathrm{NMR}$ spectroscopy and ${ }^{13} \mathrm{C}$-NMR spectroscopy. The products were assessed by DPPH method for the evaluation of antioxidant activities using Gallic acid as a reference standard. The results showed that the existence of electron-donating moieties, such as $\mathrm{Ni}$ (II) and $\mathrm{Co}(\mathrm{II})$, in the chemical structure raises the antioxidant action. In contrast, the $\mathrm{Pt}(\mathrm{IV})$ and $\mathrm{Pd}(\mathrm{II})$ complexes reduced the antioxidant activity [64].

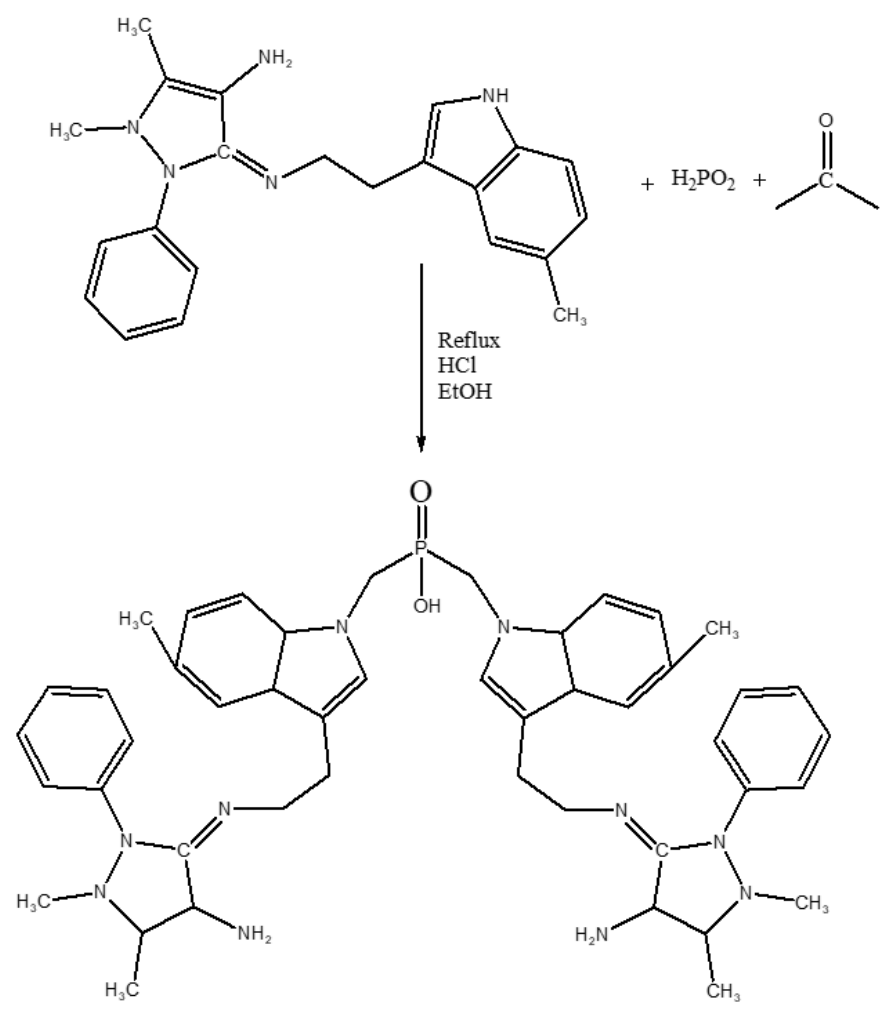

Scheme 27. Synthesis route of ligand L.

Soğukömeroğullari et al. reported a new Schiff base ligand: 1-[[1-(2-hydroxy-5methoxyphenyl)ethylidene]amino]-4-phenyl-5-benzoyl-pyrimidine-2-one, obtained from the condensation reaction of 2-hydroxy-5-methoxybenzaldehyde and 1-amino-5-benzoyl-4phenyl- $1 H$-pyrimidine-2-one, and its $\mathrm{Co}(\mathrm{II}), \mathrm{Cu}(\mathrm{II}), \mathrm{Ni}(\mathrm{II})$ and $\mathrm{Mn}(\mathrm{II})$ complexes (Scheme 29). 


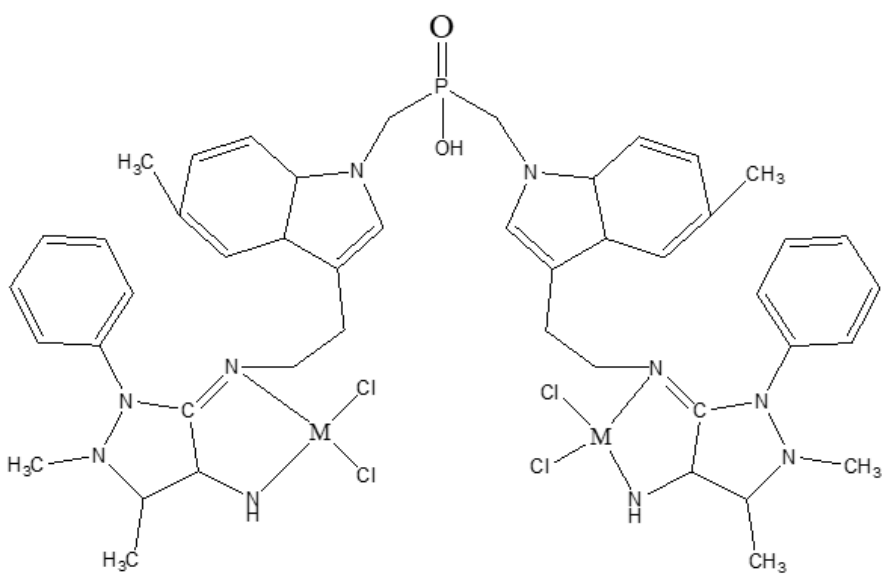

$\mathrm{M}=\mathrm{Ni}, \mathrm{Cu}, \mathrm{Zn}, \mathrm{Pd}, \mathrm{Cd}$ and $\mathrm{Hg}$

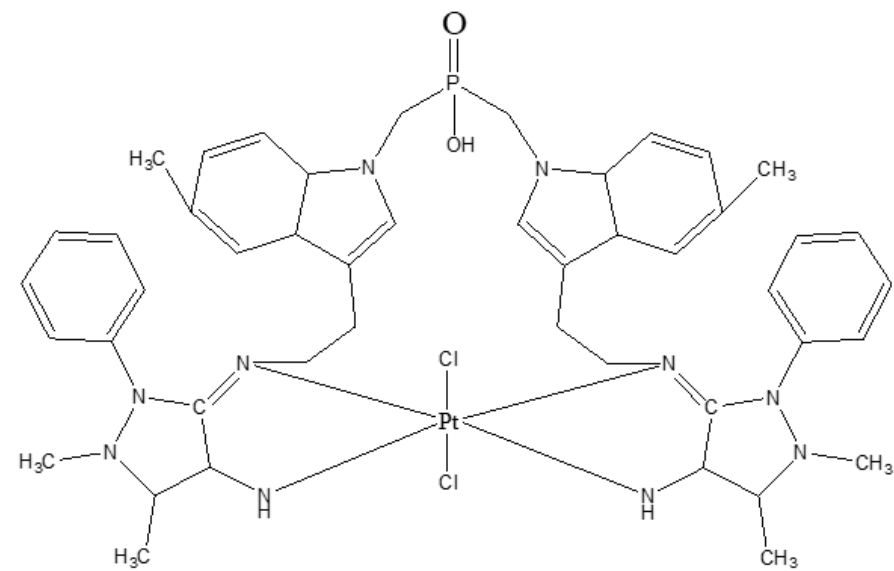

Scheme 28. Synthesis route of the complexes.

The products were characterized by IR spectroscopy, NMR spectroscopy, mass spectroscopy, and other analytical techniques. Antioxidant and antimicrobial activities of the compounds were determined. The antimicrobial properties were evaluated against Gramnegative and Gram-positive bacteria and fungi using the microdilution procedure. The evaluation of antioxidant properties of the compounds was performed against DPPH using ascorbic acid as a standard. The order of increase in free radical scavenging activity of the complexes is given as $\mathrm{Co}(\mathrm{II})>\mathrm{Cu}$ (II) $>\mathrm{Ni}$ (II) $>\mathrm{Mn}$ (II)[65].
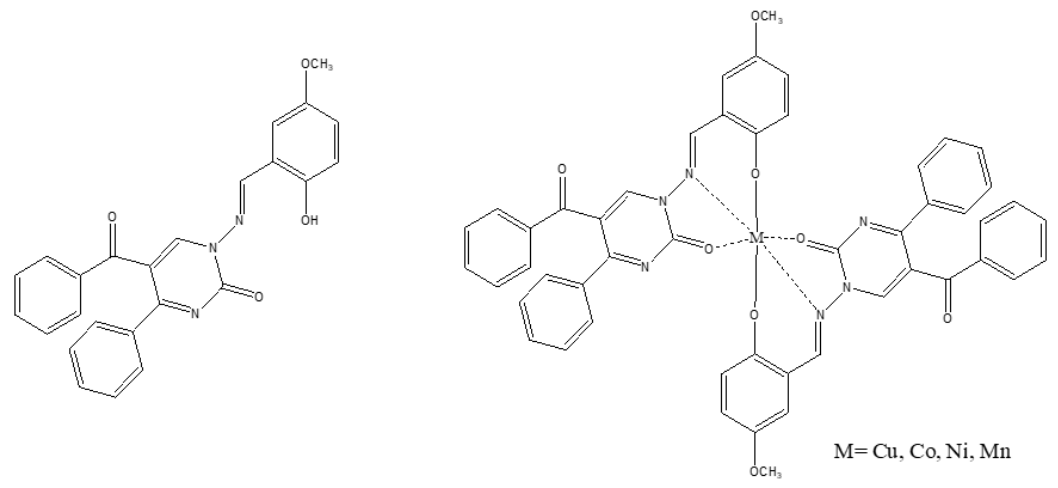

Scheme 29. Structure of Schiff base and its metal complexes.

Buldurun et al. reported a new Schiff base ligand: (Z)-1-(4-(2-hydroxy-3-methoxy benzylideneamino)phenyl)ethanone synthesized from the condensation reaction of 2-hydroxy3-methoxybenzeldehyde and 1-(4-aminophenyl) ethanone, and its $\mathrm{Fe}$ (II) and $\mathrm{Co}$ (II) complexes (Scheme 30). The complexes had coordination number six with octahedral geometry. For 
characterization of the compounds infrared spectroscopy, UV-Visible spectroscopy, ${ }^{1} \mathrm{H}-\mathrm{NMR}$ spectroscopy, X-ray diffraction analysis, elemental analysis, and thermogravimetrydifferential thermal analysis (TGA-DTA) techniques were used. The antioxidant properties of the compounds were determined using. FRAP, CUPRAC, ABTS, and DPPH methods. The reference standards used were BHA, BHT, ascorbic acid, and tocopherol. The results showed that all the compounds showed enhanced antioxidant activities as compared to the standards used [66].

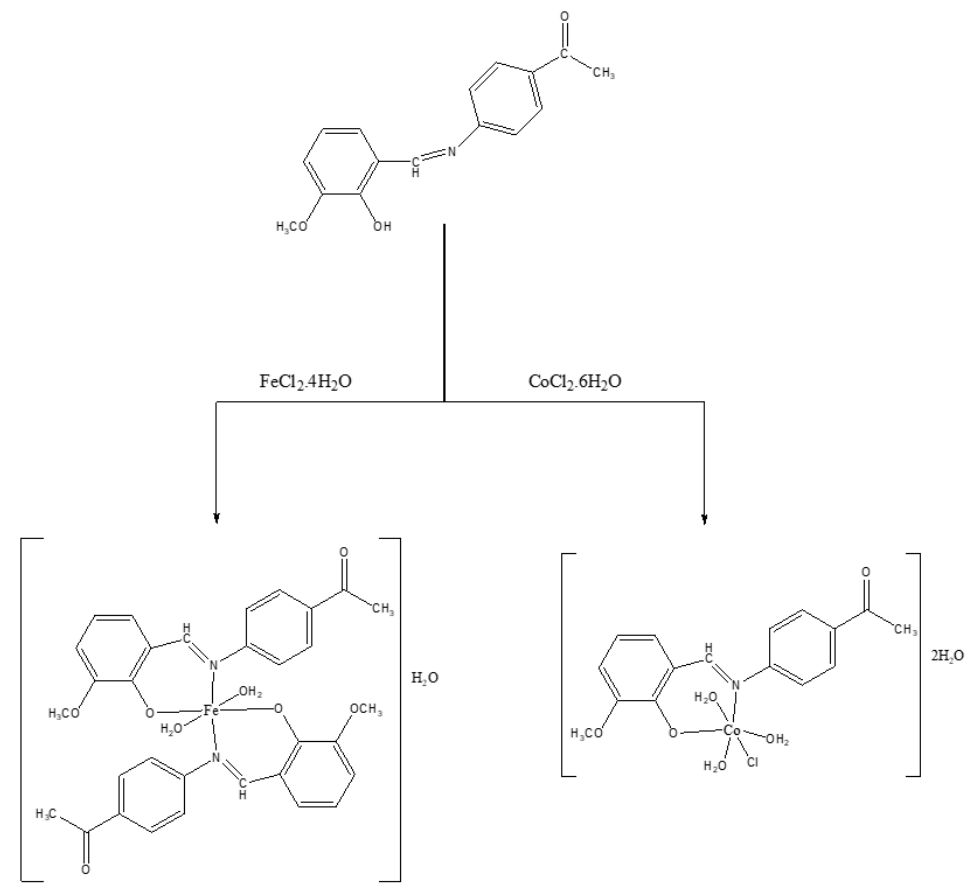

Scheme 30. Proposed structure of the Schiff base and Fe(II) and Co(II) complex compounds.

Devagi et al. synthesized four new Schiff bases: acetophenonethiosemicarbazone [HAp-tsc $\quad\left(\mathrm{HL}^{1}\right), \quad$ acetophenone-4 $(N)$-methylthiosemicarbazon [H-Ap-mtsc $] \quad\left(\mathrm{HL}^{2}\right)$, acetophenone-4 $(N)$-ethylthiosemicarbazone [H-Ap-etsc $\quad\left(\mathrm{HL}^{3}\right), \quad$ acetophenone-4 $(N)$ phenylthiosemicarbazone [H-Ap-ptsc] $\left(\mathrm{HL}^{4}\right)$, and their $\mathrm{Ru}(\mathrm{II})$ complexes with the general formula $\quad[\mathrm{RuCp}(\mathrm{Ap}-\mathrm{tsc})(\mathrm{PPh})] . \mathrm{Cl} \quad(1), \quad\left[\mathrm{RuCp}\left(\mathrm{Ap}-\mathrm{mtsc}_{3}\right)\left(\mathrm{PPh}_{3}\right)\right] . \mathrm{Cl} \quad$ (2), $\quad[\mathrm{RuCp}(\mathrm{Ap}-$ etsc) $\left.\left(\mathrm{PPh}_{3}\right)\right] . \mathrm{Cl}$ (3) and $\left[\mathrm{RuCp}(\mathrm{Ap}-\mathrm{ptsc})\left(\mathrm{PPh}_{3}\right)\right] . \mathrm{Cl}$ (4) (Scheme 31). The products were characterized by IR spectroscopy, Electronic spectroscopy, ${ }^{1} \mathrm{H}-\mathrm{NMR}$, and ${ }^{13} \mathrm{C}-\mathrm{NMR}$ spectroscopy and X-Ray diffraction. The binding ability of Bovine Serum Albumin (BSA) and calf-thymus DNA (CT DNA) to the complexes was explored by absorption and emission titration methods. DPPH method was used to explore the antioxidant activities of the complexes.

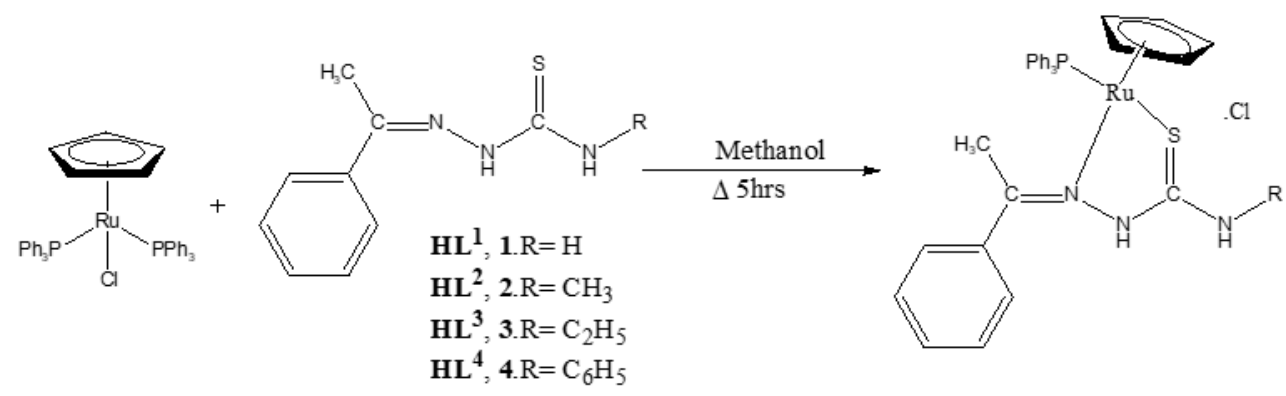

Scheme 31. General reaction for the synthesis of $\mathrm{Ru}(\mathrm{II})$ complexes. 
The results showed that these complexes had higher antioxidant capacity as compared to the ascorbic acid, used as a reference standard. The antibacterial activity of the complexes was determined against Escherichia coli, Salmonella paratyphi, Bacillus subtilis, and Staphylococcus aureus. It was clear from the results that the complex (3) showed higher antipathogenic activity [67].

The synthesis of two novel Schiff bases, namely 3-[(5-methyl-benzothiazol-2-ylimino)methyl]-naphthalen-2-ol ( $\left.\mathrm{HL}^{1}\right)$ and 3-[(5-floro-benzothiazol-2-ylimino)-methyl]-naphthalen2-ol $\left(\mathrm{HL}^{2}\right)$ have been reported from the reaction of 2-hydroxynaphthaldehyde with 2-amino-6methylbenzothiazole and 2-amino-6-florobenzothiazole respectively (Scheme 32). Nickel(II) and Copper(II) complexes of $\mathrm{HL}^{1}$ and $\mathrm{HL}^{2}$ with the general formula, $\left[\mathrm{CuL}_{1} \mathrm{ClH}_{2} \mathrm{O}\right]$, [NiL $\left.\mathrm{ClH}_{2} \mathrm{O}\right],\left[\mathrm{Cu}\left(\mathrm{L}_{2}\right)_{2}\right]$, and $\left[\mathrm{NiL}_{2} \mathrm{ClH}_{2} \mathrm{O}\right]$, were also synthesized (Scheme 33). The products were characterized by IR spectroscopy, ultraviolet visible spectroscopy, ${ }^{1} \mathrm{H}-\mathrm{NMR}$, and ${ }^{13} \mathrm{C}$ NMR spectroscopy and TGA. The results showed that the ligands are bidentate, and their complexes have four coordinated geometry. The antibacterial properties of the compounds were evaluated against Gam-negative and Gram-positive bacteria according to the method used in the literature. The antioxidant activities of the complexes were determined using FRAP and DPPH methods. The results showed that the copper complexes had the best antioxidant potentials as compared to the other compounds [68].

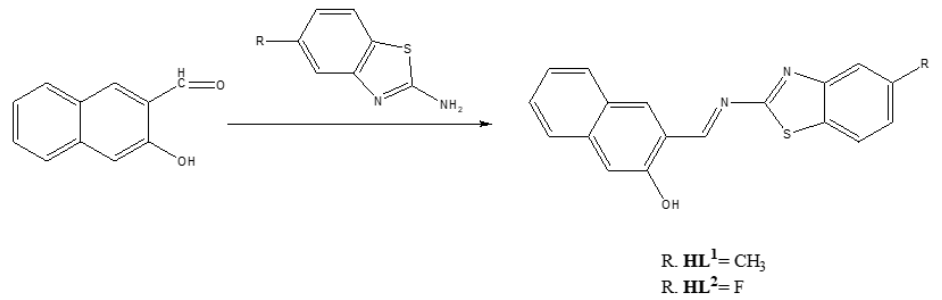

Scheme 32. Synthesis of the ligand $\mathbf{H L}^{1}$ and $\mathbf{H L}^{2}$.
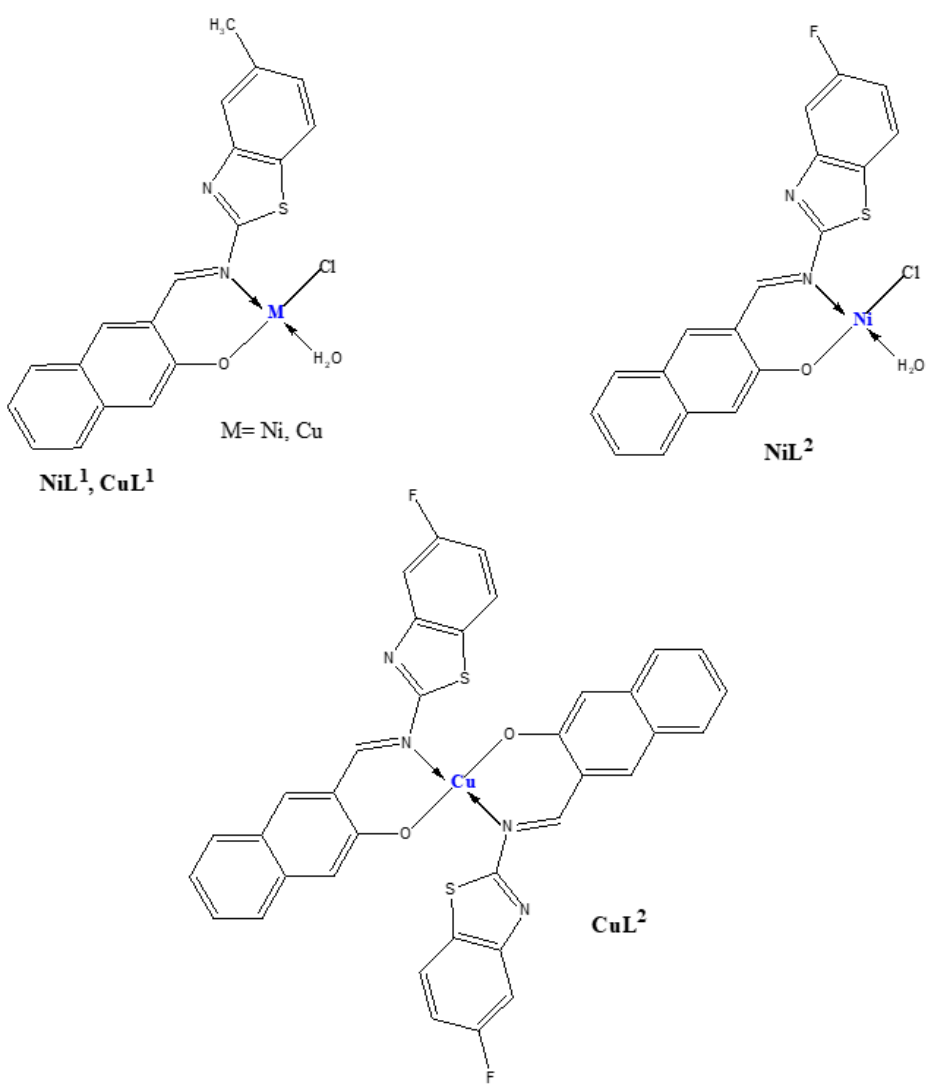

Scheme 33. Proposed structure of the complexes. 


\section{Conclusions}

Schiff bases and their metallic complexes are the most important chemical compounds having common features in most of the essential compounds and active medicinal agents. These compounds have a broad range of applications. They are widely used in industries. Schiff bases have important biological activities such as antioxidant, antibacterial, antifungal, anticancer, and antidiabetic. These compounds have the considerable chelating capacity. Generally, Schiff bases are widely investigated, but their industrial and medicinal uses need more investigation. The analysis of structure, activity, and mechanism of action of these compounds is required for the advances in this field. We have reviewed some of the critical Schiff bases and their metallic complexes that have significant antioxidant activities. Our analysis shows that $\mathrm{Cu}(\mathrm{II})$ complexes of Schiff bases have good scavenging activity compared to others like $\mathrm{Co}, \mathrm{Zn}$, and $\mathrm{Ni}$.

\section{Funding}

This research received no external funding.

\section{Acknowledgments}

The authors are thankful to the Head of the Chemistry Department, Government Degree College No.2 Mardan for his cooperation, timely suggestions, and encouragement.

\section{Conflicts of Interest}

The authors declare no conflict of interest.

\section{References}

1. Kajal, A.; Bala, S.; Kamboj, S.; Sharma, N.; Saini, V. Schiff Bases: A Versatile Pharmacophore. Journal of Catalysts 2013, 2013, 1-14, http://doi.org/10.1155/2013/893512.

2. Qin, W.; Long, S.; Panunzio, M.; Biondi, S. Schiff Bases: A Short Survey on an Evergreen Chemistry Tool. Molecules 2013, 18, 12264-12289, http://doi.org/10.3390/molecules181012264.

3. Muzammil, K.; Trivedi, P.D.K. Synthesis and Characterization of Schiff base m-nitro aniline and their complexes. Res. J. Chem. Sci. 2015, 5, 52-55.

4. Kolapwar, B.G. Study of schiff base compounds and its derivatives. Anveshana's International Journal of Research in Pharmacy and Life Sciences 2017, 2, 15-18.

5. Hameed, A.; al-Rashida, M.; Uroos, M.; Abid Ali, S.; Khan, K.M. Schiff bases in medicinal chemistry: a patent review (2010-2015). Expert Opinion on Therapeutic Patents 2017, 27, 63-79, http://doi.org/10.1080/13543776.2017.1252752.

6. Dalia, S.; Afsan, F.; Hossain, M.; Khan, M.N.; Zakaria, C.; Zahan, M.K.-E.; Ali, M. A short review on chemistry of schiff base metal complexes and their catalytic application. International Journal of Chemical Studies 2018, 6, 2859-2866.

7. Kakanejadifard, A.; Khojasteh, V.; Zabardasti, A.; Azarbani, F. New Azo-Schiff Base Ligand Capped Silver and Cadmium Sulfide Nanoparticles Preparation, Characterization, Antibacterial and Antifungal Activities. Organic Chemistry Research 2018, 4, 210-226, https://doi.org/10.22036/org.chem.2018.133383.1149.

8. Fareed, G.; Rizwani, G.; Ahmed, M.; Versiani, M.; Fareed, N. Schiff bases derived from 1aminoanthraquinone: A new class of analgesic compounds. Pakistan Journal of Scientific and Industrial Research Series A: Physical Sciences 2017, 60, 122-127.

9. Hanif, M.; Hassan, M.; Rafiq, M.; Abbas, Q.; Ishaq, A.; Shahzadi, S.; Seo, S.-Y.; Saleem, M. MicrowaveAssisted Synthesis, In Vivo Anti-Inflammatory and In Vitro Anti-Oxidant Activities, and Molecular Docking Study of New Substituted Schiff Base Derivatives. Pharmaceutical Chemistry Journal 2018, 52, 424-437, http://doi.org/10.1007/s11094-018-1835-0.

10. Malik, A.; Goyat, G.; Verma, K.K.; Garg, S. Synthesis, Spectral and Antimicrobial Studies of Some OVanillin-2-aminopyridine Schiff Base Complexes of Organyltellurium(IV). Chem. Sci. Trans. 2018, 7, 329-337, https://doi.org/10.7598/cst2018.1480. 
11. Kalaiarasi, G.; Dharani, S.; Puschmann, H.; Prabhakaran, R. Synthesis, structural characterization, DNA/protein binding and antioxidant activities of binuclear Ni(II) complexes containing ONS chelating ligands bridged by 1,3-bis(diphenylphosphino)propane. Inorganic Chemistry Communications 2018, 97, 34-38, http://doi.org/10.1016/j.inoche.2018.09.004.

12. Luo, H.; Xia, Y.; Sun, B.; Huang, L.; Wang, X.; Lou, H. Pan, W. Zhang, X. Synthesis and Evaluation of in Vitro Antibacterial and Antitumor Activities of Novel N,N-Disubstituted Schiff Bases. Biochem. Res. Int. 2017, 2017, http://doi.org/10.1155/2017/6257240.

13. Al-Shemary, R. K. Design, Synthesis and Biological Evaluation of Schiff Bases and Their Co(II), Cu(II), Ni(II) Chelates from Derivative Containing Indole Moiety Bearing-Triazole. Eur. Chem. Bull. 2017, 6, 433-439. http://doi.org/10.17628/ecb.2017.6.433-439.

14. More, G.; Bootwala, S. Z.; Mascarenhas, J.; Aruna, K. Anti-Microbial And Anti-Tubercular Activity Evaluation Of Newly. International Journal of Pharmaceutical Sciences and Research 2018, 9, 30293035, http://doi.org/10.13040/IJPSR.0975-8232.9(7).3029-35.

15. Mahmood Yousif Al-Labban, H.; Mohammed Sadiq, H.; Abduljabbar Jaloob Aljanaby, A. Synthesis, Characterization and study biological activity of some Schiff bases derivatives from 4-amino antipyrine as a starting material. Journal of Physics: Conference Series 2019, 1294, 0-8, http://doi.org/10.1088/17426596/1294/5/052007.

16. Shreekanta, S.A.; Venkatesh, T.V.; Naik, P.P. Murugendrappa, N. Bulk Electroorganic Synthesis of Schiff Bases and Their Electrical Behaviour. IOSR Journal of Applied Chemistry 2013, 3, 31-35.

17. Bader, N. Applications of Schiff's bases chelates in quantitative analysis: A review. Rasayan Journal of Chemistry 2010, 3, 660-670.

18. Alorabi, Q.A.; Abdelbaset, M.; Zabin, A.S. Colorimetric Detection of Multiple Metal Ions Using Schiff Base 1-(2-Thiophenylimino)-4-(N-dimethyl)benzene. $\quad$ Chemosensors $\quad 2020, \quad 8$, http://doi.org/10.3390/CHEMOSENSORS8010001.

19. Uddin, M.N.; Khandaker, S.; Moniruzzaman; Amin, M.S.; Shumi, W.; Rahman, M.A.; Rahman, S.M. Synthesis, characterization, molecular modeling, antioxidant and microbial properties of some Titanium(IV) complexes of schiff bases. Journal of Molecular Structure 2018, 1166, 79-90, http://doi.org/10.1016/j.molstruc.2018.04.025.

20. Al Zoubi, W.; Al-Hamdani, A.A.S.; Kaseem, M. Synthesis and antioxidant activities of Schiff bases and their complexes: a review. Applied Organometallic Chemistry 2016, 30, 810-817, http://doi.org/10.1002/aoc.3506.

21. Bitu, N.A.; Hossain, S.; Zahid, A.A.S.M.; Zakaria, C.M. Anti-pathogenic Activity of Cu ( II ) Complexes Incorporating Schiff Bases : A Short Review. American Journal of Heterocyclic Chemistry 2019, 5, 1123, http://doi.org/10.11648/j.ajhc.20190501.14.

22. Kuddushi, M.M.Y.; Malek, M.A.H.; Patidar, V.L.; Patel, M.S.; Patel, R.K.; Dave, R.H. Synthesis And Characterization Of Schiff Base Aniline With 5- Bromo -2- Hydroxyl Benzaldehyde And Their Metal Complexes. International Journal of Recent Scientific Research 2018, 9, 26026-26030.

23. Lobo, V.; Patil, A.; Phatak, A.; Chandra, N. Free radicals, antioxidants and functional foods: Impact on human health. Pharmacogn. Rev. 2010, 4, 118-126, http://doi.org/10.4103/0973-7847.70902.

24. Pham-Huy, L.A.; He, H.; Pham-Huy, C. Free radicals, antioxidants in disease and health. Int J Biomed Sci 2008, 4, 89-96.

25. Suleman, M.; Khan, A.; Baqi, A.; Kakar, M.S.; Samiullah.; Ayub, M. Antioxidants, its role in preventing free radicals and infectious diseases in human body. Pure Appl. Biol. 2018, 7, 380-388, http://doi.org/10.19045/bspab.2018.700197.

26. Ibrahim, M.; Khan, A.; Ikram, M.; Rehman, S.; Shah, M.; Nabi, H.H.; Achuchaogu, A.A. In Vitro Antioxidant Properties of Novel Schiff Base Complexes. Asian J. Chem. Sci. 2017, 2, 1-12, http://doi.org/10.9734/ajocs/2017/32244.

27. Zehiroglu, C.; Ozturk Sarikaya, S.B. The importance of antioxidants and place in today's scientific and technological studies. Journal of Food Science and Technology 2019, 56, 4757-4774, http://doi.org/10.1007/s13197-019-03952-X.

28. Akbarirad, H.; Gohari Ardabili, A.; Kazemeini, S. M.; Mousavi Khaneghah, A. An overview on some of important sources of natural antioxidants. Int. Food Res. J. 2016, 23, 928-933.

29. Al-Amiery, A.A.; Kadhum, A.A.H.; Mohamad, A.B. Antifungal and Antioxidant Activities of Pyrrolidone Thiosemicarbazone Complexes. Bioinorganic Chemistry and Applications 2012, 2012, http://doi.org/10.1155/2012/795812.

30. Rahman, M.M.; Islam, M.B.; Biswas, M.; Khurshid Alam, A.H.M. In vitro antioxidant and free radical scavenging activity of different parts of Tabebuia pallida growing in Bangladesh. BMC Research Notes 2015, 8, 1-9, http://doi.org/10.1186/s13104-015-1618-6.

31. Kurutas, E.B. The importance of antioxidants which play the role in cellular response against oxidative/nitrosative stress: current state. Nutrition Journal 2016, 15, 1-22, http://doi.org/10.1186/s12937016-0186-5.

32. Engwa, G.A. Free radicals and the role of plant phytochemical as antioxidants against oxidative stressrelated diseases. IntechOpen 2012, http://doi.org/10.5772/intechopen.76719. 
33. Socea, L.I.; Visan, D.C.; Barbuceanu, S.F.; Apostol, T.V.; Bratu, O.G.; Socea, B. The antioxidant activity of some acylhydrazones with dibenzo [a,d][7] annulene moiety. Rev. Chim. 2018, 69, 795-797, http://doi.org/10.37358/rc.18.4.6202.

34. Taghvaei, M.; Jafari, S.M. Application and stability of natural antioxidants in edible oils in order to substitute synthetic additives. Journal of Food Science and Technology 2015, 52, 1272-1282, http://doi.org/10.1007/s13197-013-1080-1.

35. Neloofar; Ali, N.; Khan, A.; Amir, S.; Khan, N.A.; Bilal, M. Synthesis of schiff bases derived from 2hydroxy-1-naphthaldehyde and their Tin(II) complexes for antimicrobial and antioxidant activities. Bull. Chem. Soc. Ethiop 2017, 31, 445-456, http://doi.org/10.4314/bcse.v31i3.8.

36. Mahmood, I.; Mahmood, T. Synthesis of schiff bases from natural products and their synthesis of schiff bases from natural products and their remarkable antimicrobial and antioxidant activity. FUUAST J. Biol. 2014, 4, 27-32.

37. Guo, Z.; Xing, R.; Liu, S.; Yu, H.; Wang, P.; Li, C.; Li, P. The synthesis and antioxidant activity of the Schiff bases of chitosan and carboxymethyl chitosan. Bioorg Med Chem Lett 2005, 15, 4600-4603, http://doi.org/10.1016/j.bmcl.2005.06.095.

38. Chen, F.; Shi, Z.; Neoh, K.G.; Kang, E.T. Antioxidant and antibacterial activities of eugenol and carvacrolgrafted chitosan nanoparticles. Biotechnology and Bioengineering 2009, 104, 30-39, http://doi.org/10.1002/bit.22363.

39. Ying, G.Q.; Xiong,W.Y.; Wang, H.; Sun, Y.; Liu, H.Z. Preparation, water solubility and antioxidant activity of branched-chain chitosan derivatives. Carbohydr. Polym. 2011, 83, 1787-1796, http://doi.org/10.1016/j.carbpol.2010.10.037.

40. Hu, D.C.; Chen, L.W.; Yang, Y.X.; Liu, J.C. Syntheses, structures and antioxidant activities of two new $\mathrm{Cu}$ (II) complexes with a benzimidazole schiff base ligand. Inorg. Nano-Metal Chem. 2018, 1556, http://doi.org/10.1080/15533174.2013.843562.

41. Ünlüer, D.; Ersan, B.; Ünver, Y. Schiff base derivatives with morpholine and antioxidant activity. Turk $J$ Anal Chem. 2019, 1, 8-10.

42. Rao, D.P. A review on versatile applications of noval schiff bases and their metal complexes. Letters in Applied NanoBioScience 2019, 8, 675-681, https://doi.org/10.33263/LIANBS84.675681.

43. Al Khalida, A.A.; Dunya Lafta, A.L.D.; Ahmed, A.A.; Abdul Amir Hassan, K. Synthesis of Schiff base Metal Complexes with Motivating Scavenging Potential Studies. Free Radicals and Antioxidants 2019, 9 , 1-4, http://doi.org/10.5530/fra.2019.1.1.

44. Salem, H.F.; Alzletni, H.A.; El-ajaily, M.M.; Eghreibeel, H.M. Antimicrobial Activity and Antioxidant Studies of (Z) -2- (2-Methoxybenzylideneamino ) - 3-Methylbutanoic Acid with Mixed Ligand Chelates. A. S. Microbiology 2019, 2, 7-12.

45. Ejidike, I.P.; Ajibade, P.A. Synthesis, Characterization, Antioxidant, and Antibacterial Studies of Some Metal (II) Complexes of Tetradentate Schiff Base Ligand : (4E) -4- [(2- \{(E) - [1- (2,4-Dihydroxyphenyl) ethylidene] amino $\}$ ethyl) imino] pentan-2-one. Bioinorganic Chemistry and Applications 2015, 2015, 1-9, http://doi.org/10.1155/2015/890734.

46. Nagavolu, V.R.; Velusamy,S.; Chechugari, S.; Yalavarthi, P.R.; Karani, M. Synthesis and in-vitro antioxidant activity of novel schiff bases and azetidines derived from phenyl urea derivatives. Indian J. Pharm. Educ. Res. 2017, 51, S707-S711, http://doi.org/10.5530/ijper.51.4s.102.

47. Kubra, N.K.; Suganya, A.; Saranya, J.; Lakshmi, S.S. Biological Activities of Schiff Bases and Their Copper (II) Complexes. World Journal of Pharmaceutical Research 2018, 7, 951-959, http://doi.org/10.13140/RG.2.2.28195.96808.

48. Bakır, T.K.; Lawag, J.B. Preparation, characterization, antioxidant properties of novel Schiff bases including 5-chloroisatin-thiocarbohydrazone. Research on Chemical Intermediates 2020, 46, 2541-2557, http://doi.org/10.1007/s11164-020-04105-y.

49. Boulguemh, I.E.; Beghidja, A.; Khattabi, L.; Long, J.; Beghidja, C. Monomeric and dimeric copper (II) complexes based on bidentate $\mathrm{N}^{\prime}$-(propan-2-ylidene) thiophene carbohydrazide Schiff base ligand: Synthesis, structure, magnetic properties, antioxidant and anti-Alzheimer activities. Inorganica Chimica Acta 2020, 507, http://doi.org/10.1016/j.ica.2020.119519.

50. Bingöl, M.; Turan, N. Schiff base and metal(II) complexes containing thiophene-3-carboxylate: Synthesis, characterization and antioxidant activities. Journal of Molecular Structure 2020, 1205, http://doi.org/10.1016/j.molstruc.2019.127542.

51. Yüksel, E.; Bilici, A.; Geçibesler, İ.H.; Kaya, İ. Synthesis and antioxidant activities of phenolic Schiff base monomers and polymers. Canadian Journal of Chemistry 2020, 98, 151-157, http://doi.org/10.1139/cjc2019-0307.

52. Horozić, E.; Suljagić, J.; Suljkanovic, M. Synthesis, characterization, antioxidant and antimicrobial activity of Copper(II) complex with Schiff base derived from 2,2-dihydroxyindane-1,3-dione and Tryptophan. American Journal of Organic Chemistry 2019, 9, 9-13.

53. Akocak, S.; Lolak, N.; Tuneg, M.; Boga, M. Antioxidant, acetylcholinesterase and butyrylcholinesterase inhibition profiles of histamine schiff bases. J. Turkish Chem. Soc. Sect. A Chem. 2019, 6, 157-164, http://doi.org/10.18596/jotcsa.521291. 
54. Akocak, S.; Lolak, N.; Vullo, D.; Durgun, M.; Supuran, C.T. Synthesis and biological evaluation of histamine Schiff bases as carbonic anhydrase I, II, IV, VII, and IX activators. Journal of Enzyme Inhibition and Medicinal Chemistry 2017, 32, 1305-1312, http://doi.org/10.1080/14756366.2017.1386660.

55. Ali Alomari, A.; Ibrahim, M.M.; Mohamed, M.E. Schiff bases of hydroxyacetophenones and their copper(II) and nickel(II) complexes: Synthesis, antioxidant activity and theoretical study. Asian J. Chem. 2016, 28, 2505-2511, http://doi.org/10.14233/ajchem.2016.20055.

56. Bora, G.; Gogoi, D.; Saikia, S.; Pareek, A.; Handique, J.G. Stannous chloride catalyzed synthesis of Schiff bases from hydroxybenzaldehydes and determination of their antioxidant activity by ABTS and DPPH assay. Journal of Chemical Sciences 2019, 131, http://doi.org/10.1007/s12039-019-1645-2.

57. Al-Duhaidahawi, D.L.; Jabir, M.S.; Al-Amiery, A.A.; Moneim, A.E.A.; Alkaim, A.F.; Kadhum, A.A.H. Novel antioxidants compounds derived from isatine. Biochem. Cell. Arch. 2018, 18, 709-713.

58. Muthukumar, R.; Shakila, D.; Karthik, A.D.; Geetha, K.G. Synthesis, Spectroscopic Investigation and inVitro Antioxidant Activity Of Schiff Base Copper(II) Complex. World Journal of Pharmaceutical Research 2018, 7, 757-766.

59. Oloyede-Akinsulere, A.I.; Olalekan Babajide, J.; Salihu, S.O. Synthesis, Antibacterial and Antioxidant Activities of Some Tridentate Substituted Salicylaldimines. Asian J. Appl. Chem. Res. 2018, 1, 1-10.

60. Al-Amery, M.H.A.; Al-Sahlanee, T.Q.M. Synthesis, characterization, antioxidant and anticancer human studies of new metal ion complexes of poly schiff base derived from 4-aminoacetophenone with 4chloroaniline and salicylaldehyde. Res. J. Chem. Environ. 2019, 23, 200-227, http://doi.org/10.22159/ajpcr.2018.v11i11.29837.

61. Demetgül, C.; Beyazit, N. Synthesis, characterization and antioxidant activity of chitosan-chromone derivatives. Carbohydr. Polym. 2018, 181, 812-817, http://doi.org/10.1016/j.carbpol.2017.11.074.

62. Ejidike, I.P.; Ajibade, P.A. Synthesis, Characterization, Anticancer, and Antioxidant Studies of Ru(III) Complexes of Monobasic Tridentate Schiff Bases. Bioinorg. Chem Appl. 2016, 2016, 1-11, http://doi.org/10.1155/2016/9672451.

63. Nevin, T.; Ahmet, S.; Kenan, B.; Yusuf, A.; Ragıp, A. Synthesis and Chemical Structure Elucidation of Two Schiff Base Ligands, Their Iron(II) and Zinc(II) Complexes, and Antiradical, Antimicrobial, Antioxidant Properties. Letters in Organic Chemistry 2016, 13, 343-351, http://doi.org/10.2174/1570178613666160422161855.

64. Al Zoubi, W.; Kim, M.J.; Salih Al-Hamdani, A.A.; Kim, Y.G.; Ko, Y.G. Phosphorus-based Schiff bases and their complexes as nontoxic antioxidants: Structure-activity relationship and mechanism of action. Applied Organometallic Chemistry 2019, 33, 1-16, http://doi.org/10.1002/aoc.5210.

65. Soğukömeroğullari, H.G.; Sönmez, M.; Berber, İ. Synthesis, characterization, antioxidant and antimicrobial studies of $\mathrm{Cu}(\mathrm{II}), \mathrm{Co}(\mathrm{II}), \mathrm{Ni}(\mathrm{II})$ and $\mathrm{Mn}(\mathrm{II})$ complexes with a new schiff base ligand containing a pyrimidine moiety. Int. J. PharmTech Res. 2016, 9, 391-398.

66. Buldurun, K.; Turan, N.; Bursal, E.; Mantarc1, A.; Turkan, F.; Taslimi, P.; Gülçin, İ. Synthesis, spectroscopic properties, crystal structures, antioxidant activities and enzyme inhibition determination of $\mathrm{Co}(\mathrm{II})$ and $\mathrm{Fe}(\mathrm{II})$ complexes of Schiff base. Research on Chemical Intermediates 2020, 46, 283-297, http://doi.org/10.1007/s11164-019-03949-3.

67. Devagi, G.; Dallemer, F.; Kalaivani, P.; Prabhakaran, R. Organometallic ruthenium(II) complexes containing NS donor Schiff bases: Synthesis, structure, electrochemistry, DNA/BSA binding, DNA cleavage, radical scavenging and antibacterial activities. Journal of Organometallic Chemistry 2018, 854, 1-14, http://doi.org/10.1016/j.jorganchem.2017.10.036.

68. Ekennia, A.C.; Osowole, A.A.; Olasunkanmi, L.O.; Onwudiwe, D.C.; Ebenso, E.E. Coordination behaviours of new (bidentate N,O-chelating) Schiff bases towards copper(II) and nickel(II) metal ions: synthesis, characterization, antimicrobial, antioxidant, and DFT studies. Research on Chemical Intermediates 2017, 43, 3787-3811, http://doi.org/10.1007/s11164-016-2841-z. 